\title{
A METHODOLOGY FOR MODELING THE MIGRATION OF EOR CHEMICALS IN FRESH WATER AQUIFERS
}

B. Royce, M. Garre11, 1 A. Kahn, and E. Kaplan

$$
\text { November } 1983
$$

\author{
Prepared for the \\ BARTLESVILLE ENERGY TECHNOLOGY CENTER \\ ORDER NO. DE-AP 19-82BC99996 \\ U.S. DEPARTMENT OF ENERGY
}

${ }^{1}$ Dept. of Physics \& Energy Studies, Adelphi University, Garden City, NY 11530

ENV IRONMENTAL SYSTEMS ANALYSIS GROUP

DEPARTMENT OF APPLIED SCIENCE

BROOKHAVEN NATIONAL LABORATORY

ASSOCIATED UNIVERSITIES, INC.

Under Contract No. DE-AC02-76CH00016 with the

U.S. Department of Energy 


\section{DISCLAIMER}

This report was prepared as an account of work sponsored by an agency of the United States Government. Neither the United States Government nor any agency Thereof, nor any of their employees, makes any warranty, express or implied, or assumes any legal liability or responsibility for the accuracy, completeness, or usefulness of any information, apparatus, product, or process disclosed, or represents that its use would not infringe privately owned rights. Reference herein to any specific commercial product, process, or service by trade name, trademark, manufacturer, or otherwise does not necessarily constitute or imply its endorsement, recommendation, or favoring by the United States Government or any agency thereof. The views and opinions of authors expressed herein do not necessarily state or reflect those of the United States Government or any agency thereof. 


\section{DISCLAIMER}

Portions of this document may be illegible in electronic image products. Images are produced from the best available original document. 
TABLE OF CONTENTS

List of Tables....................................... v

List of Figures..................................... v

Abstract.............................................. vi

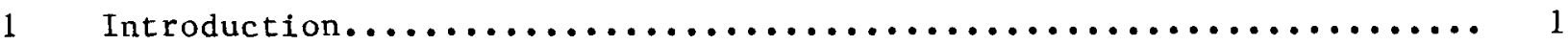

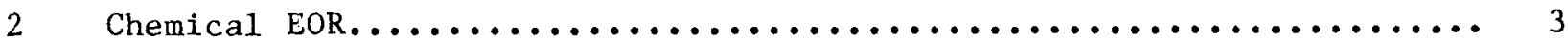

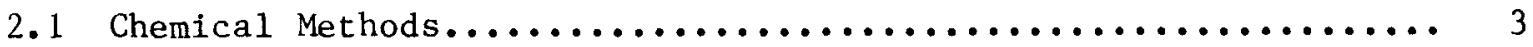

2.1.1 Micellar-Polymer (Surfactant) Flooding............... 3

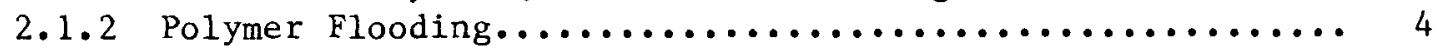

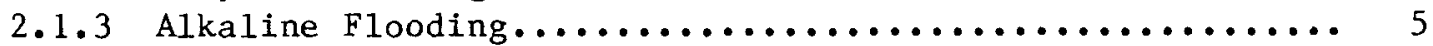

2.2 Chemicals Used in EOR: Data Survey and Application........... 5

2.3 Chemicals Used in EOR: Health Effects................... 5

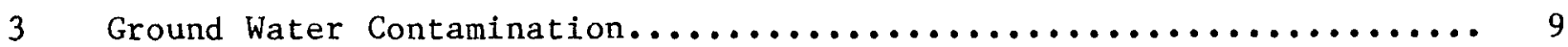

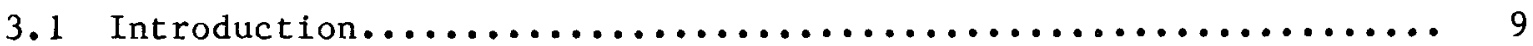

3.2 Flow Through Porous Media.............................. 9

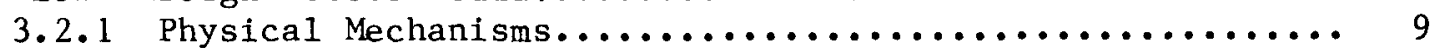

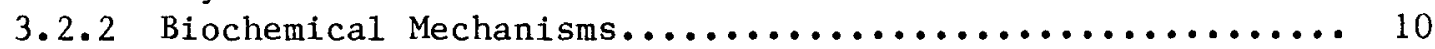

3.3 Interactions of EOR Chemicals with Porous Media............. 10

3.4 An Overview of Aquifer Contamination..................... 14

3.4.1 Contamination from EOR Chemicals................. 16

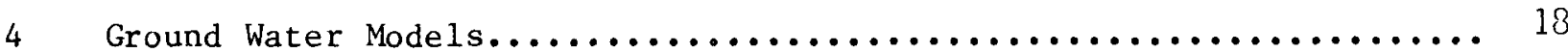

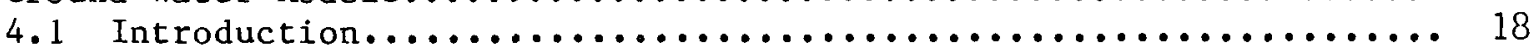

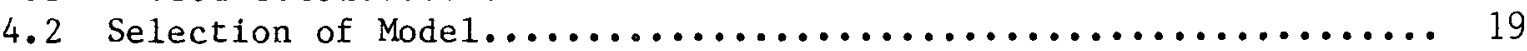

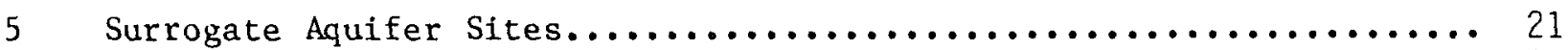

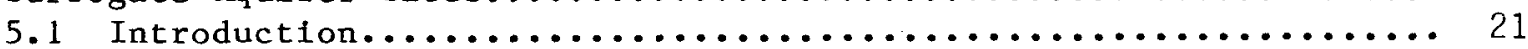

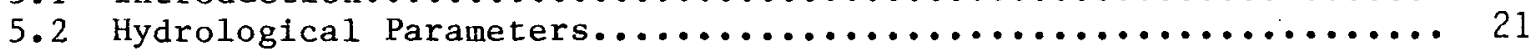

5.2.1 Parameters to Estimate Physical Properties of Aquifer 21

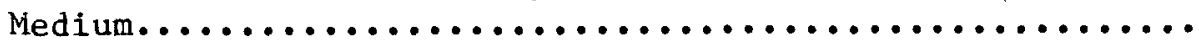

5.2.2 Parameters to Estimate Dynamic Properties of Fluid...... 21

5.3 Aquifer Descriptions.............................. 22

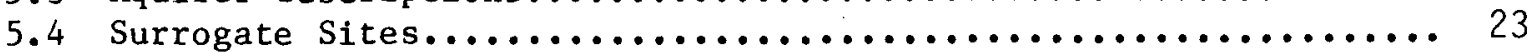

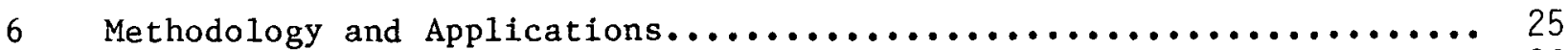

6.1 Hypothetical Polyacrylamide Releases.................... 26

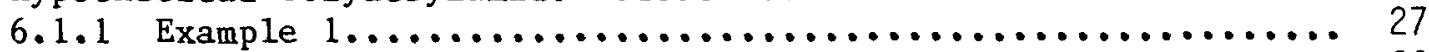

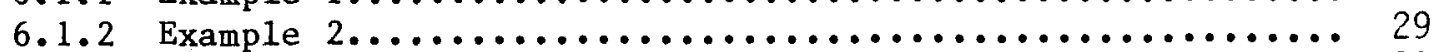

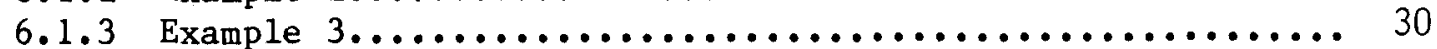

6.1 .4 Summary of Polyacrylamide Examples.................. 32

6.2 Hypothetical Petroleum Sulfonate Releases................. 33

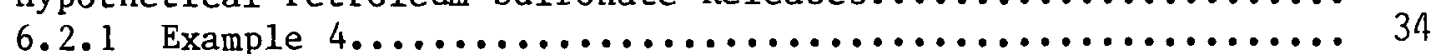

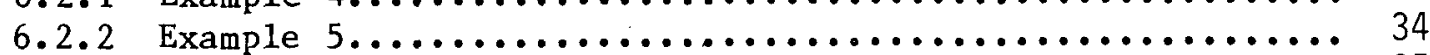

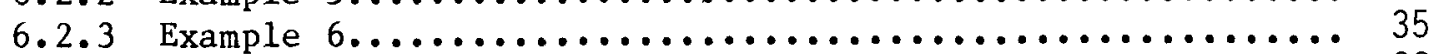

6.2.4 Summary of Petroleum Sulfonate Examples.............. 39 
$7 \quad$ Summary and Conclusions............................. 42

7.1 EOR and Ground Water Contamination................... 42

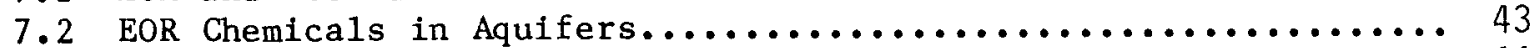

7.3 Ground Water Modeling of Surrogate Aquifer Sites............ 44

7.4 Conclusions................................. 45

References...................................... 47 


\section{LIST OF TABLES}

2.1 Toxicity and Related Data for Typical EOR Chemicals........... 7

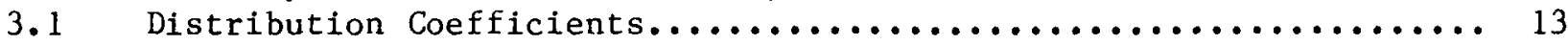

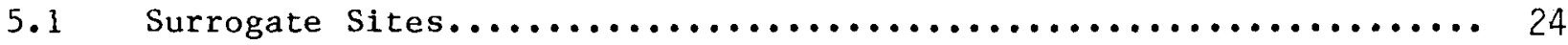

6.1 Range of Retardation Factors for Various Polyacrylamide

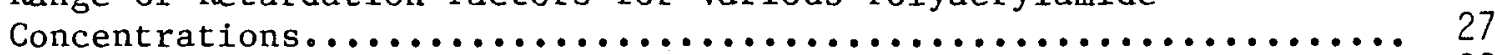

6.2 Summary of Input Parameters for Polymer Examples............... 28

6.3 Summary of Plume Descriptions for Polymer Examples............. 32

6.4 Range of Retardation Factors for Various Petroleum Sulfonate 33

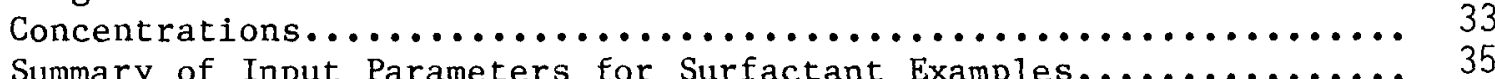

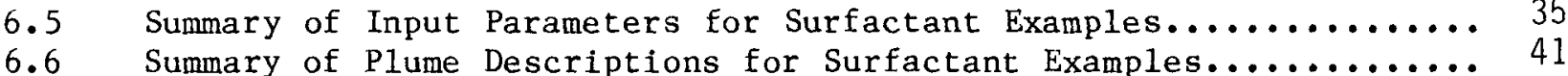

\section{LIST OF FIGURES}

3.1 Contaminant pathways into fresh water aquifers............... 15

6.1 Concentration of polyacrylamides from example 1 at aquifer site A.. 29

6.2 Concentration of polyacrylamides from example 2 at aquifer site A.. 30

6.3 Concentration of polyacrylamides fron example 3 at aquifer site B.. 31

6.4 Concentration of petroleum sulfonates from example 4 at aquifer

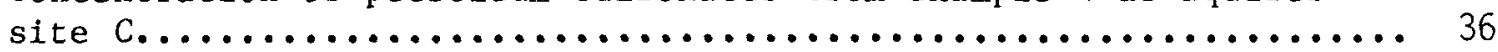

6.5 Concentration of petroleum sulfonates from example 5 at aquifer

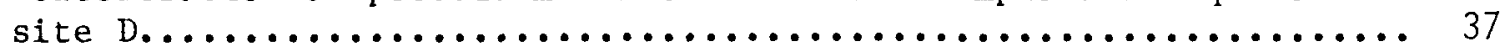

6.6 Concentration of petroleum sulfonates from example 5 at aquifer

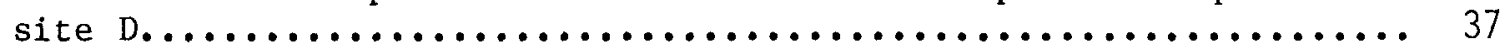

6.7 Concentration of petroleum sulfonates from example 5 at aquifer

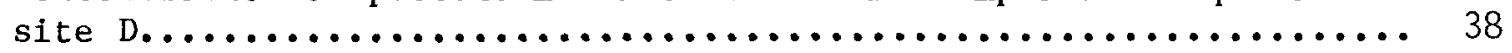

6.8 Concentration of petroleum sulfonates from example 6 at aquifer

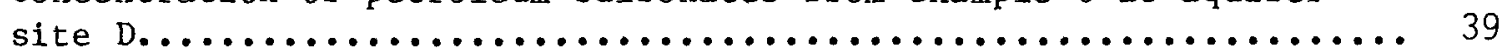

6.9 Concentration of petroleum sulfonates from example 6 at aquifer

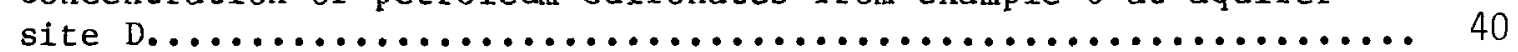

6.10 Concentration of petroleum sulfonates from example 6 at aquifer site D........................................... 40 
ABSTRACT

The objective of this study is to develop a method for modeling the transport of EOR chemicals accidentally released to fresh water aquifers. Six examples involving hypothetical releases of EOR chemicals at surrogate aquifer sites are used to illustrate the application of this method. Typical injection rates and concentrations of EOR chemicals used at current or proposed projects were obtained from the literature and used as the basis for the hypothetical accidents. Four surrogate aquifer sites were selected from States where chemical flooding methods are employed. Each site is based on real hydrological data but presented in such a way to avoid identification with existing EOR fields. A significant amount of data is required to model ground water systems. The hypothetical examples help to indicate the type of data needed. The computer results illustrate that high levels of contamination are possible for many years. In addition, due to these high levels of contamination, it is possible for contaminants to migrate offsite of the EOR field. There are a variety of pathways through which EOR chemicals could be accidentally released to fresh water aquifers during normal EOR operations. There is insufficient EOR experience to date, however, to forecast risks accurately. 


\section{INTRODUCTION}

Tertiary recovery or enhanced oil recovery (EOR) is an important source of energy for the future. It could produce an additional one quarter to one third of the estimated 312 billion barrels of oil in place in the United States, including offshore and Alaska, after conventional recovery has been exhausted. The three major categories of tertiary methods are thermal processes, miscible displacement, and chemical flooding. Estimates of maximum production rates from these methods range from 750 thousand to more than five million barrels per day. ${ }^{-5}$ However, the dependence of enhanced recovery on the petroleum products market, world oil prices, and front-end payoffs is so critical that actual EOR may not reach the upper part of this range for some time.

A number of reports ${ }^{5-10}$ have addressed the potential environmental impacts associated with various EOR technologies and conclude that most of the problems can be solved. In each given technology certain impacts are much more important than others. Air quality problems outweigh all others in steamflooding because of the sheer volume of air pollutants produced in a large project. Miscible floods might present problems involving specific reservoirs and communications between all zones and aquifers. In chemical EOR, the subject of this report, water availability and the possibility of ground water contamination are the chief problems. The subject of water availability has been treated in greater detail in previous reports.11,12 This paper addresses the potential for ground water contamination associated with EOR.

Two major sources of ground water contamination common to all forms of petroleum production are oil from producing wells and brine from wells used for underground injection. Specific to tertiary production alone is possible ground water contamination from EOR chemicals such as polymers and surfactants, or from other agents associated with chemical flooding such as bactericides and oxygen scavengers.

The chances of a major discharge of EOR chemicals into valuable fresh water aquifers have been reduced considerably because of extensive knowledge of fields in which chemical EOR is applied, because of safeguards used in construction of modern injection we11s, and because of the methods used to conserve the expensive chemicals employed in some chemical floods. Nevertheless, aquifer contamination is a particularly serious situation because natural flushing times in aquifers can exist on the order of centuries ${ }^{13}$ and because recovery costs are often prohibitive. A case of ground water contamination from chemicals allegedly used in a polymer flood in Pennsylvania already exists, 14 and, should chemical EOR ever become extensive in some of the country's older oflfields like those in the Appalachians, unplugged and abandoned unlogged older wells would make the risk of aquifer contamination from migrating fluids particularly high.

It is not the intention of this report to be alarmist nor is it an objective of this study to estimate the risk or probability of a contamination event. The purpose of this study is to estimate the extent of movement 
of chemicals specific to chemical flooding accidentally released to fresh water aquifers. The migration of these chemicals is evaluated using an existing numerical model. ${ }^{5}$ Problems that might arise from improper disposal of drilling muds, fluids used in cleaning wellbores, or the great quantities of oilfield brines are potential subjects for further investigation. 


\section{CHRMICAL EOR}

This chapter briefly discusses various forms of chemical EOR and describes the different chemicals used in each technique. The chemicals themselves are discussed in detail, with special attention paid to stability, degradation, and interaction between chemicals (in solution) and rock strata or aquifers. Much of the information used in this section was obtained with the cooperation of many companies which manufacture and/or test EOR chemicals. Some of it was obtained from journals and published reports, from textbooks, and from the literature distributed by chemical manufacturers.

\subsection{CHEHICAL METHODS}

Chemical EOR is the most complex of all EOR techniques and has been the slowest to gain widespread use. Although a 1976 National Petroleum Council Report ${ }^{4}$ predicted that chemical methods would produce some 150 thousand barrels of tertiary oil per day by 1985, current production is less than one tenth that figure, and estimates depend on how one classifies "tertiary" oil. One reason for the discrepancy is the high cost of EOR chemicals, which translates into a low rate of return from these techniques. It has been suggested in a recent conference in New Mexico that chemical methods could recover much more oil if operators were willing to settle for a $10 \%$ rate of return. 16

Chemical methods still face problems of development and applicability. Injected chemicals must be compatible with crude oils, formation waters, and the chemistry of reservoir rocks. For example, in saline reservoirs of the Gulf Coast divalent calcium and magnesium ions increase interfacial tension and hinder most chemical floods. Many chemicals are also sensitive to high reservoir temperatures and high salinity. In addition to general problems, some particular chemicals also have specific problems. The clays in some reservolr rocks adsorb sulfonates used in surfactant floods and some popular polymers suffer shear degradation at high flow rates.

Three predominant chemical EOR processes are micellar-polymer, polymer, and alkaline flooding methods. The first theoretically recovers all oil in the region of the reservoir that is swept and is considered to have the highest promise. The two latter methods are simpler and considerably less expensive. A brief discussion of each of these three chemical methods is presented below.

\subsubsection{Micellar-Polymer (Surfactant) Flooding}

In a micellar-polymer or surfactant flood, a detergent-like chemical is injected into a reservoir to improve recovery by reducing interfacial tension. Generally there are four different phases of fluid injection: a preflush to adjust reservoir salinity, a micellar solution to reduce interfacial tension, a tapered polymer slug containing either polyacrylamides or polysaccharides to provide mobility control, and a water drive to push both the micellar and polymer solutions through the reservoir. 
The micellar solution generally consists of a surfactant, cosurfactants, hydrocarbons, and salt. Micellar slug design is critical because the surfactant, usually a petroleum sulfonate, affects interfacial tension and is essential to the recovery process. Adsorption onto reservoir rock can break down the slug and reduce its ability to mobilize oil while high salinities and high concentrations of divalent ions also reduce the effectiveness of petro-sulfonates. In cases where a preflush to tolerable salinity. levels is not feasible, it still may be possible to design surfactants that can operate effectively at high salinity levels. This concept has been successfully applied by Exxon in a pilot test at the Louden Field in Fayette County, Illinois. ${ }^{7}, 18$. The surfactant was specifically designed to be effective in this field where the formation water contained over 100,000 ppm of total dissolved solids and more than 4,000 ppm of divalent ions. This pilot test was performed without a preflush and recovered $60 \%$ of the residual oil.

Two different concepts have been developed in using surfactants. These are the injection of a large quantity, 15-60\% pore volume, of dilute surfactant or the injection of a smaller quantity of highly concentrated surfactant.19 Surfactant slug designs vary in slug size, and in concentrations of surfactants, cosurfactants, and electrolytes.

\subsubsection{Polymer Flooding}

Polymers of high molecular weights (to ten million or more) may be used to thicken injection water used in waterfloods. Thus the viscosity of displacing fluid is increased, which improves both mobility ratio and sweep efficiency. Although improved waterfloods do not recover as much of the remaining oil in place as surfactant floods, they are cheaper and simpler and are applied more extensively.

Current1y both polyacrylamides and polysaccharides are used in improved waterfloods. The former are synthetic polymers which not only increase the viscosity of the injected water but also reduce the permeability of the reservoir rock. Such polymers are susceptible to mechanical breakage and shear degradation and lose their effectiveness in highly saline solutions or solutions with high concentrations of divalent ions. Biopolymers such as xanthan gum, produced by the bacterium Xanthamonous campestris, are relatively insensitive, to salinity and divalent ions and resist mechanical breakage. However, they are extremely susceptible to bacterial attack and may plug some formations. Because dissolved oxygen promotes chemical degradation of both hydrolyzed polyacrylamides and polysaccharides, oxygen scavengers such as sodium hydrosulfite or additives such as formaldehyde are often employed. 20 Some chemical additives also have the advantage of increasing thermal stability.

In improved waterflooding as in the polymer injection phase of surfactant flooding, a tapered polymer slug. with a typical initial concentration of

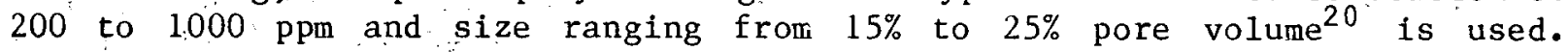




\subsubsection{Alkaline Flooding}

The term alkaline flooding refers to the use of a group of compounds, sodium hydroxide, sodium silicate, and sodium carbonate, which form in situ surfactants in a reservoir by interacting with petroleum acids. Sweep efficiency and mobility ratios are reportedly improved in such floods, but the effectiveness depends on the acids of the reservoir oil, the character of the oil-bearing rock, and the rock around the injection zone. For example, divalent ions interfere with the formation of in situ surfactants, while interaction with the chemical constituents of the rock consumes the caustic agents.

\subsection{CHEMICALS USED IN BOR: DATA SURVEY AND APPLICATION}

More than 40 manufacturers and distributors were contacted to obtain physical and chemical data including degradation for the most commonly used EOR chemicals. Twenty private firms and one university laboratory responded by sending their most current reports on several properties of the chemicals in question, particularly adsorption, degradation, and toxicity. A number of reprints from the chemical literature were also supplied. These provided data on adsorption mechanisms, physical modeling, and adsorption as a function of concentration for surfactants, polymers, and cosurfactants. The result of this survey was the assembly of data on 30 EOR surfactants, cosurfactants, and polymers. This information was compiled and used as some of the input parameters for the ground water model.

From the perspective of potential ground water contamination, it is important to consider the amounts and concentrations of chemicals typically used at EOR projects. While chemicals may be delivered to fields in concentrated forms, they may be diluted to varying degrees before injection. Information on injection amounts and concentrations are frequently published for polymers and surfactants but is not as readily available for many additives. Some of this information is considered proprietary and is difficult to obtain. The analyses performed in this study were limited to those EOR chemicals for which sufficient data were available in the open literature. It is recognized that combinations of chemicals which might appear as contaminants (e.g.,...brine containing surfactant, cosurfactant, polymer, and/or scavenger) could also pose threats to ground waters and should not be overlooked. However, these were not included in this study because the necessary physical and chemical data on their behavior were not available.

\subsection{CHEMICALS USED IN EOR: HEALTH EFFECTS}

Chemicals used in enhanced recovery can be classified according to their organic families. Silvestro and Desmarais ${ }^{21}$ classified them according to general use as mobility control agents, cosurfactants, biocides, oxygen scavengers, chelating agents, surfactants, and alkaline flooding agents. Their report evaluated more than 200 chemicals proposed for use in EOR for toxicity and potential health effects based upon existing literature.

In ground water the presence of representatives from any of the above groups of EOR chemicals might be a problem, depending on relative 
concentration, toxicity, and other related health effects, such as skin irritations or allergic reactions. For example although both polyacrylamides and polysaccharides used as mobility control agents are essentially non-toxic, the presence of a small quantity of the monomer in solution with hydrolized polyacrylamide would present a health risk because acrylamide monomer is a severe neurotoxin and cumulative poison. The American Conference of Governmental and Industrial Hygienists gives a standard for acrylamide monomer of less than one part per million by weight in potable water. Fortunately polyacrylamides are often crosslinked and the chances that monomers will leach out of solution are sma11; moreover commercial grades of polyacrylamide should contain no more than $0.05 \%$ acrylamide monomer by weight. 21

Most of the commonly used chemical cosurfactants are alcohols of the $\mathrm{C}_{5}-\mathrm{C}_{12}$ fatty acids which have low toxicities. Many of the common anionic surfactants are long chain linear alkyl sulfonates, alkyl aryl sulfonates, and petroleum sulfonates which are toxic if ingested, irritating to eyes and skin, and might provide vehicles for the uptake of hazardous chemicals because of their abilities to make those chemicals soluble. Alkyl aryl sulfonates and petroleum sulfonates are usually used in the form of sodium salts, and the aryl groups in the former include benzene, toluene, xylene, and naphthalene. Although sulfonates are not fully characterized toxicologically, both the petroleum and aryl species have demonstrable relations to tumors. 21

Some of the biocides, bactericides, and oxygen scavengers could present problems if present in solution as ground water contaminants. Some phenolic compounds and their metabolites are toxic, while their co-contaminants, dioxins and furans, have potential long term environmental consequences. The strong irritant formaldehyde, useful as an additive in EOR, can have considerable dermal and respiratory effects ${ }^{21}$ and has a high acute toxicity as we11. Many chemicals used in alkaline flooding or in EOR pre-flushes are caustic or acidic in nature and have substantial health-related effects.

Many of the chemical additives used in EOR operations are frequently transported to the field and stored in a drum as a pure or concentrated chemical. In actual use, many of these chemicals are mixed on the surface and considerably diluted prior to injection to subsurface reservoirs. Based on this, it would appear that these particular chemicals could pose more of a risk to ground water contamination while stored at the surface than during injection. The possibility of a purely accidental spill or loss of chemicals to a subsurface formation does exist resulting mainly from carelessness or ignorance on the part of the oil field operator. However, even the smallest loss of chemicals reduces the economic efficiency of the operation and thus would be avoided by proper management.

A summary of health data for a representative group of EOR chemicals is found in Table 2.1. From the table it appears that some EOR chemicals mentioned in this chapter might indeed pose hazards to field personnel and to populations which use aquifers near or underneath tertiary fields as sources of drinking water. Nevertheless, such hazards could be substantially reduced by safe handling, by carefully following occupational safety and health regulations, by proper disposal, and by strictly adhering to Underground Injection Control (UIC) regulations. 
Table 2.1

Toxicity and Related Data for Typical EOR Chemicals

(from Reference 21 and manufacturer's data)

\section{Mobility Control Agents}

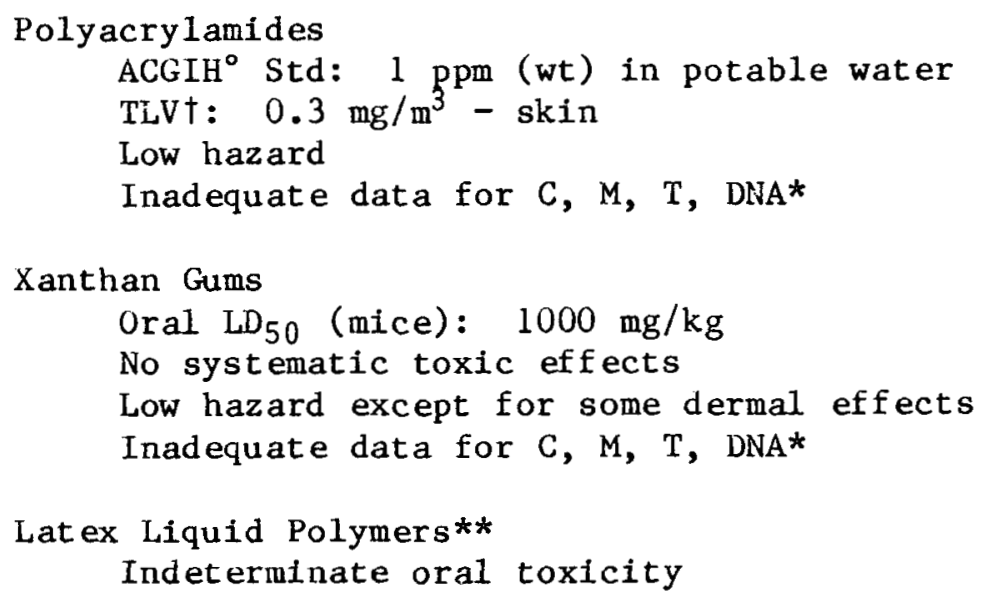

\section{Cosurf actants}
Polyethoxylated nonylpheno1**
$\mathrm{LD}_{50}$ (rats) >1500 $\mathrm{mg} / \mathrm{kg}$
for whole series

1-2 Octano1

Oral $\mathrm{LD}_{50}$ : unknown but $500 \mathrm{mg} / \mathrm{kg}$ reported in human poisoning

Aquatic Toxicity: for $\mathrm{LC}_{50}: 10-100 \mathrm{ppm}$

Low hazard except for moderate dermal effects

Insufficient or inadequate data for $C, M, T, D N A$ *

Alkylphenyl polyether alcohols (nonionic)**

(rats) $\mathrm{LD}_{50}>1500 \mathrm{mg} / \mathrm{kg}$

for whole series

Alkylaryl polyethylene glycol, ethers, alcohols

Low toxicity - chronic, dermal

Moderate subacute, acute toxicity

Low respiratory hazard.

Insufficient data for $C, M, T$, DNA*

\section{Biocides, Oxygen Scavengers, Chelating Agents}

Pheno1

Human 1ethal dose: $140 \mathrm{mg} / \mathrm{kg}$

TLVt: < $0.001 \mathrm{mg} /$ drinking water

Oral $L_{50}$ (rats): $414 \mathrm{mg} / \mathrm{kg}$

High hazard - toxic with respiratory and dermal effects, plus allergic reactions

Possible $C$, inadequate data $M, T$, DNA* 
Tab1e 2.1 (continued)

III. Biocides, Oxygen Scavengers, Chelating Agents (continued)

Formaldehyde

Oral $\mathrm{LD}_{50}$ (rats) $-800 \mathrm{mg} / \mathrm{kg}$

TLVt: $3 \mathrm{mg} / \mathrm{m}^{3}$

Low to moderate chronic toxicity

Moderate to high hazard - other toxicities

Inad equate data for $C, M, T$, DNA*

IV. Surfactants (Anionic)

NaDDBS - Sodium dodecylbenzene sulfonate**

$\mathrm{LD}_{50}$ (rats) -- $2.77 \mathrm{~g} / \mathrm{kg}$

Na-alkylaryl sulfonates

Ural $\mathrm{L}_{50}$ (rats) $-2.32 \mathrm{~g} / \mathrm{kg}$

Lethal human dose -- 500-5000 $\mathrm{mg} / \mathrm{kg}$

Low to moderate toxicities

Insufficient data $C, M, T$, DNA*

Petroleum sulfonates

Recommended treatment as potential carcinogen

Low to moderate toxicity

Petroleum products linked to skin cancer

Inad equate data $\mathrm{M}, \mathrm{T}$, $\mathrm{DNA}^{*}$

\section{Alkaline Flooding Chemicals}

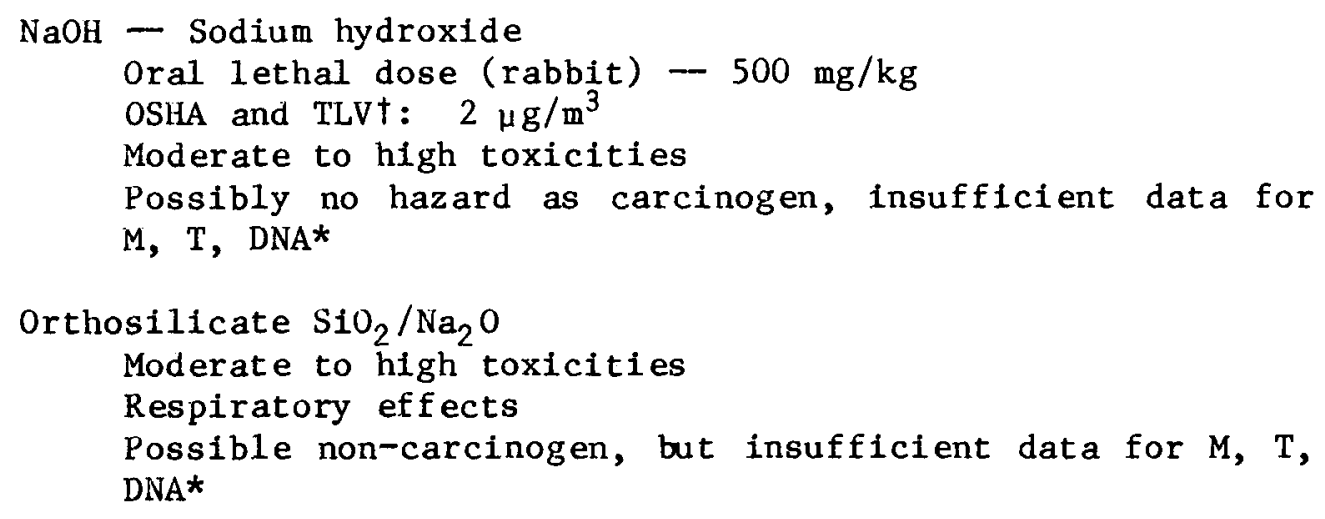

${ }^{\circ}$ ACGIH: American Conference of Governmental \& Industrial Hygienists. TTLV: Threshold Limit Value.

$*_{C}=$ carcinogenicity, $T=$ teratogenicity, $M=$ Mutagenicity; DNA $=$ DNA damage. **Manufacturer's Data.

$\mathrm{LD}_{50}=$ Lethal dose $50 \%$ kill.

$\mathrm{LD}_{50}=$ Lethal concentration $50 \%$ kil1.

OSHA = Occupational Safety and Health Administration. 


\section{GROUND WATER CONTAMINATION}

\subsection{INTRODUCTION}

An increased amount of ground water is used as a resource every year. Rough1y $95 \%$ of the world's usable fresh water (i.e., not including icecaps and glaciers) comes from aquifers. ${ }^{22}$ Currently $25 \%$ of fresh water utilized in the U.S. is obtained from the ground. Approximately 50\% of all U.S. residents rely on it as their primary source of drinking water. ${ }^{23}$ In the western states at least $46 \%$ of domestic water supplies and $44 \%$ of water required for industrial needs is pumped from aquifers. 22 Contamination has frequently gone unnoticed in the past because the ground water around industrial disposal sites was not used for public drinking supplies. Subsurface contamination, however, has become a major concern in recent years. As the use of ground water continues to rise in the future, additional cases of contamination will receive attention.

Fresh water aquifers possess several characteristics which make them both a valuable resource and one much threatened by contamination. Because biodegradation and aeration play only a small role in cleansing subsurface water, ground water is particularly prone to long term contamination. Biodegradation of organic chemicals in aquifers takes place at approximately one-tenth of the average rate in surface waters. ${ }^{24}$ Another characteristic of ground water is that it is slow moving. It commonly takes subsurface water hundreds of years to reenter the water cycle. Residence time ranges from two weeks in a water table or recharge aquifer to 10,000 years in a confined aquifer. 22

\subsection{FLOW THROUGH POROUS MEDIA}

The movement of contaminants in solution in an aquifer is affected by mechanisms such as advection, dispersion, diffusion, degradation, and entrapment. These mechanisms can be categorized as either physical or chemical and are described in more detail below.

\subsubsection{Physical Mechanismś}

Physical mechanisms include advection, mechanical entrapment, hydrodynamic dispersion, and molecular diffusion. Advection is the component of contaminant movement attributable to the flowing ground water. ${ }^{22}$ Mechanical entrapment is the plugging of a flow in a pore neck by molecules with diameters larger than the channel. 25,26. Entrapment will cause a decrease in the total concentration of constituent flowing through a porous medium. Anderson describes hydrodynamic dispersion as the mixing and spreading of particles caused in part by molecular diffusion: and by microscopic variations in velocities within individual pores. ${ }^{27}$ In the presence of large heterogeneities, dispersion occurs as contaminants more selectively around less permeable units of the formation. Dispersion affects the transportation of constituents by spreading the particles through the path of least resistance. This mechanism acts to dilute the original solute concentration 
during transportation. The measurement of dispersion, quantified through the coefficient of dispersion, will be discussed in Chapter Five. In situations where there is little flow along the gradient and/or low velocity, diffusion plays a larger role than dispersion. Molecular diffusion results spontaneously from the natural transfer of mass between adjacent layers of fluid in laminar flow due to a concentration gradient. 28

\subsubsection{Biochemical Kechanisms}

Biodegradation occurs at a less frequent rate in ground water; roughly one-tenth the rate in surface waters. Most degradation is in the form of oxidation or reduction. Oxidation-reduction reactions are chemical processes often initiated by biological activity. Oxidized particles are less mobile than reduced forms.

Shallow aquifers can have significant bacterial activity. ${ }^{29}$ There are bacterial populations native to aquifers and, in addition, inoculation can occur easily during the process of drilling a well or injecting materials through one. ${ }^{24}, 30$ Recent data indicate that chemicals, such as benzene and the linear alcohol ethoxylates and sulfonates, degrade at a constant rate of 2 to $4 \%$ per week. ${ }^{24}, 30-32$ This 1 s a first order decay rate which holds true only for concentrations of up to 100 grams per liter. ${ }^{24}, 30$

There are only a few studies currently investigating bacterial activity in ground water and these have been restricted to shallow recharge aquifers. It is generally presumed, however, that there is considerably less bacterial activity in deep artesian aquifers. A project has recently begun at Brookhaven National Laboratory which will examine biological activity in deep aquifers. 33

\subsection{INTERACTIONS OF EOR CHEMICALS WITH POROUS MEDIA}

The transport of contaminants in ground water is governed by flow fields and by chemical and biochemical reactions which alter concentrations and chemistry. Mechanisms which come into play include adsorption, desorption, acid-base reactions, solution and precipitation, reduction and oxidation, ion-pairing or formation of complexes, microbial synthesis, and radioactive decay. In one-dimensional, single-phase, steady-state flow within a homogeneous saturated medium, the partial differential equation for concentration of a contaminant as a function of spatial coordinate $x$ and time $t$ is $^{22}$ :

$$
D_{x} \frac{\partial^{2} C}{\partial x^{2}}-v_{x} \frac{\partial C}{\partial x}+\frac{\rho_{b}}{n} \frac{\partial S}{\partial t}=\frac{\partial C}{\partial t}
$$

where

$$
\begin{aligned}
C(x, t) & =\text { concentration } \\
v_{x} & =\text { velocity along flow direction }
\end{aligned}
$$




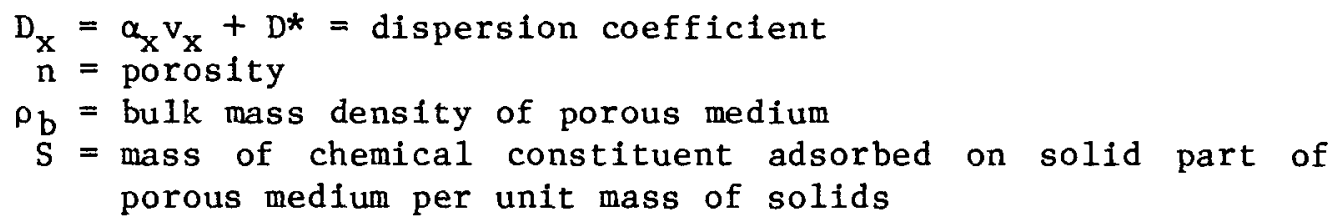

By approximating in a linear region

$$
\begin{aligned}
& S \approx K_{d} C \\
& K_{d}=\text { distribution coefficient }
\end{aligned}
$$

and the third term on the left becomes

$$
-\frac{\rho_{b}}{n} K_{b} \frac{\partial C}{\partial t}
$$

Thus the solute transport equation can be rewritten as

$$
D_{x} \frac{\partial^{2} C}{\partial x^{2}}-v_{x} \frac{\partial C}{\partial x}=\left(1+\frac{\rho_{b} K_{d}}{n}\right) \frac{\partial C}{\partial t} \text {. }
$$

It has yet another useful form if $\rho_{b}, K_{d}, n$, and $D_{x}$ are assumed to be constant coefficients, and a source term for production of contaminants is inserted.

where

$$
\frac{\partial}{\partial x}\left(\frac{D_{x}}{R_{d}} \frac{\partial C}{\partial x}\right)-\frac{v_{x}}{R_{d}} \frac{\partial C}{\partial x} \pm C_{S} Q=\frac{\partial C}{\partial t}
$$

$$
R_{\mathrm{d}}=\left(1+\frac{\rho_{\mathrm{b}} \mathrm{K}_{\mathrm{d}}}{\mathrm{n}}\right)
$$

The first two terms on the left in Eq. 3.3 represent dispersion and advection mechanisms respectively. The third term represents the production or source term. The retardation factor $R_{d}$, defined by 3.4 , effectively reduces the velocity of flow of reactive or adsorbed contaminants. The retardation factor is affected by the density and porosity of the media through which it is flowing and by the adsorptive properties of the contaminant in the specific inedia.

The parameters and coefficients needed for solving Equation 3.3 are important. Values of $\mathrm{K}_{\mathrm{d}}$ in inverse density units can be obtained from case studies and published reports of adsorption studies. For reactive slugs with $0 \leq \mathrm{K}_{\mathrm{d}} \leq 10^{3} \mathrm{~cm}^{3} / \mathrm{g}$ and for typical $\rho_{\mathrm{b}} / \mathrm{n}$ values from 4 to $10 \mathrm{gm} / \mathrm{cm}^{3}$, retardation factors can range from unity (solute flowing with ground water) to $10^{4}$ (immobile solute). 
$\mathrm{K}_{\mathrm{d}}$ data for polymers and surfactants used in this report are presented in Table 3.1.34-40 Calculations for this table were made from research papers and quantities are only approximate. Broad ranges refer to various experimental conditions, including brine solutions, $\mathrm{pH}$, use of additives, etc. Under certain conditions chemicals like biocides, chelating agents, oxygen scavengers, preflush agents, or alkaline flooding chemicals remain in solution once they get into aquifers. Hence they are not adsorbed, $K_{d} \simeq 0$, and $\mathrm{k}_{\mathrm{d}} \sim 1$.

Regardless of which methods are employed to solve the equations of solute transport, e.g., analytic, finite difference, or random walk modeling, solutions would be altered by timewise degradation of the solute. Such degradation, either biological or chemical, would reduce concentrations in stepwise or exponential fashion.

Unfortunately, precise data on degradation of EOR solutes is difficult to obtain. Partially hydrolyzed polyacrylamide solutions change their viscoelastic behavior ${ }^{4}$ and degrade mechanically when injection pressures are high. Within the oil reservoir, mechanical degradation affects the mobility of the polymer banks. However, under low pressures at low flow rates like those which might occur in many fresh water aquifers, further degradation of polyacrylamides has not been studied and such degradation might be assumed to be negligible, particularly under aerobic conditions.

Dilute solutions of biopolymers lose viscosity at higher temperatures, probably due to redox reactions involving free radicals. Formulations involving combinations of radical transfer agents, easily oxidizable alcohols, compatible oxygen scavengers, biocides, and sufficient brine concentration, retard viscosity loss of these biopolymers significantly. 42 Hence, stable solutions of biopolyners like xanthan gum are obtainable and degradation of the overall slugs would be negligible unless or until their chemistry changed.

Nonionic surfactants like long chain ethoxylated alcohols would be found in EOR applications as cosurfactants. The biodegradation of different types of nonionic surfactants has most recently been studied through electrochemical methods based on adsorption phenomena at charged electrodes and based on ${ }^{14} \mathrm{CO}_{2}$ evolution. In the former tests Triton $\mathrm{X}$ series alcohols showed degrees of biodegradation ranging from 17.6 to $52.6 \%$ over five days. ${ }^{43}$ In the latter, alkyl and ethoxylated chains of $C_{16} E_{3}$ were. seen to degrade in Ohio River water with a half life of roughly 1.6 days. ${ }^{31}$ Studies of the degradability of the anionic surfactants specific to EOR do not seem to be available at this time. 
Table 3.1

Distribution Coefficients

\begin{tabular}{|c|c|c|c|c|c|c|c|}
\hline \multirow[b]{2}{*}{ Ref. } & \multirow[b]{2}{*}{ Material } & \multirow[b]{2}{*}{ itfg. } & \multirow[b]{2}{*}{ Ads. Medium } & \multirow[b]{2}{*}{ Testing Kange } & \multirow[b]{2}{*}{ Linear Region } & \multicolumn{2}{|c|}{$\mathrm{K}_{\mathrm{d}}$ Ranges $\left(\mathrm{cm}^{3} / \mathrm{g}\right)$} \\
\hline & & & & & & Low & High \\
\hline \multicolumn{8}{|c|}{ POLMIERS } \\
\hline 34 & $\begin{array}{l}\text { Actigum }(X-12 \\
\text { Polysaccharide }\end{array}$ & $\begin{array}{c}\text { CHKA } \\
\text { S.A. }\end{array}$ & Quartz & to $1000 \mathrm{ppm}$ & $<100 \mathrm{ppm}$ & 0 & 7.4 \\
\hline 35 & $\begin{array}{l}\text { Yolyacrylamides } \\
2.7 \times 10^{6} \mathrm{~g} / \mathrm{mol} \\
\text { and } \\
1.0 \times 10^{6} \mathrm{~g} / \mathrm{mol}\end{array}$ & & Quartz & to $800 \mathrm{ppm}$ & $<60 \mathrm{ppm}$ & 1.73 & 5.63 \\
\hline & $11 \times \mathrm{xl}^{6} \mathrm{~g} / \mathrm{mol}$ & SEPYIC & Montmorillonite & to $800 \mathrm{ppm}$ & \multicolumn{3}{|c|}{$\begin{array}{l}\text { if } 20-25 \% \text { hydrolized } \\
<800 \mathrm{ppm} \\
\text { if } 15 \% \text { hydrolized }\end{array}$} \\
\hline \multicolumn{8}{|c|}{ COSURPACTANIS } \\
\hline 36 & $\begin{array}{l}\text { Neodol Series } \\
2-9,3-9 \\
4-9,5-9\end{array}$ & Shell & $\begin{array}{l}\text { Crushed } \\
\text { Berea SS }\end{array}$ & to $3 \%$ & $<0.1 \%$ & & 2.7 \\
\hline 36 & $2-9$ & & Bahama Dolite & to $2 \%$ & $<0.2 \%$ & & 0.88 \\
\hline 36 & $25-35$ & $\downarrow$ & Crushed Berea SS & to $35000 \mathrm{ppm}$ & $<2200 \mathrm{ppm}$ & 0.13 & 1.3 \\
\hline 36 & Triton Series & $\begin{array}{l}\text { Rohm } \\
\& \text { Haas }\end{array}$ & & & & & \\
\hline 36 & $x-100$ & & Berea SS & $\begin{array}{l}\text { to } 28000 \mathrm{ppm} \\
\text { at } 0.2 \mathrm{~N} \mathrm{~N} \mathrm{NaCl}\end{array}$ & $<1000 \mathrm{ppm}$ & & 3.77 \\
\hline 36 & $x-100,102,165,305$ & & Berea SS & $\begin{array}{l}\text { to } 28000 \mathrm{ppm} \\
\text { at } 1.0 \mathrm{~N} \mathrm{NaC1}\end{array}$ & $<1000 \mathrm{ppm}$ & 0.57 & 1.65 \\
\hline 37 & $x-100$ & & $\begin{array}{l}\text { Crushed Hired } \\
\text { Berea }\end{array}$ & to $2600 \mathrm{ppm}$ & & & \\
\hline \multicolumn{8}{|c|}{ IONIC SURPACTAMIS } \\
\hline 38 & NaDuCS & & Kaolinite & to $10 \mathrm{mM} / \mathrm{l}$ & $<6 \mathrm{~mm} / \mathrm{l}$ & & 4.29 \\
\hline 38 & NaUDis & & Na Kaolinite & to $50 \mathrm{mM} / \ell$ & $\begin{array}{l}<5 \mathrm{~mm} / \mathrm{l} \\
\text { or } \\
2000 \mathrm{ppm}\end{array}$ & 2.0 & 12.5 \\
\hline 一 & \multicolumn{7}{|c|}{ PEIMOLERI SUIFONATES } \\
\hline 39 & Alconate 80 & Witco & Lona Novia & to $1600 \mathrm{ppm}$ & $<100$ ppm & 5 & 25 \\
\hline 39 & Bryton 430 & Conoco & Loma Novia & to $800 \cdot \mathrm{ppm}$ & $<100 \mathrm{ppm}$ & & 12.5 \\
\hline 39 & Saponate & Witco & Loma Novia & to $800 \mathrm{ppm}$ & $<100 \mathrm{ppm}$ & & 5.0 \\
\hline$\underline{39}$ & Pyronate 50 & witco & Loma Novia & to 800 ppp & $\leq 100$ ppo & -- & -5.0 \\
\hline \multicolumn{8}{|c|}{ COSURFACTANI - SLRFACTANT COMBNATIONS } \\
\hline 36 & $\begin{array}{l}\text { Neodol 25-30 } \\
\text { + Bryton } 4303: 7\end{array}$ & $\begin{array}{l}\text { Shell } \\
\text { Conoco }\end{array}$ & $\begin{array}{l}\text { Crushed } \\
\text { Berea SS }\end{array}$ & to $35000 \mathrm{ppm}$ & $<2200 \mathrm{ppm}$ & 1.0 & 5.0 \\
\hline 40 & $\begin{array}{l}\text { PIM } 337 \\
+ \text { SBA 1:1.75 }\end{array}$ & & $\begin{array}{l}\text { Berea Core } \\
\text { with oil }\end{array}$ & to $10900 \mathrm{ppm}$ & not plotted & $\begin{array}{c}0.044 \\
\text { for various }\end{array}$ & $\begin{array}{r}0.11 \\
\text { floods }\end{array}$ \\
\hline 40 & $\begin{array}{l}\text { Texas No. } 1 \\
+\mathrm{n} \text {-propanol 1:6 }\end{array}$ & & $\begin{array}{l}\text { Berea Core } \\
\text { with oil }\end{array}$ & $\begin{array}{l}\text { to } 2850 \mathrm{ppm} \\
\text { Texas No. } 1 \\
\end{array}$ & not plotted & $\begin{array}{c}0.175 \\
\text { for various } \\
\end{array}$ & $\begin{array}{r}0.35 \\
\text { floods } \\
\end{array}$ \\
\hline
\end{tabular}




\subsection{AN OVERVIEW OF AQUIFER CONTAMINATION}

There are several pathways through which contaminants can reach an aquifer. A surface spill or leaky storage container can lead to contaminants leaching through the soil and into the water table. During the process of injecting into or punping out a well a second pathway exists, namely cracks in the well casing due to corrosion or excess pressure, which can result in a direct release into an aquifer. Another source of contamination occurs when injected chemical fluids do not travel directly into the intended disposal layer but instead follow fissures and fractures in rock strata, migrate through semipermeable layers, or escape through abandoned wells which act as capillaries into an aquifer. Figure 3.1 illustrates these different aquifer contamination pathways.

The documentation of actual cases of ground water contamination is difficult for several reasons. Frequently the fresh water aquifer is not being utilized at the time contamination occurs, thus the pollution is discovered after the fact. In such cases there is no record of the source of pollution nor of the quantity which entered the ground. When the contamination comes from the slow (years to decades) leaching of wastes from a storage area or landfill it is very difficult to determine the initial pollutant concentration and load. Also it is hard to trace contaminants back to the source and to the date contamination occurred. One site on the EPA's most hazardous waste disposal list is in Laramie, Wyoming. There is no way of determining the initial mass or concentration of contamination at this site because the disposal of wastes occurred over a century. ${ }^{44}$

Searches to find a documented case of chemical contamination of an aquifer where the initial mass or concentration could be approximated and where the direction and distance of travel was known lead to the conclusion that ground water monitoring in the past has been incomplete. Forty people from five federal offices, eleven states, and a number of universities and private industries were contacted. ${ }^{14}, 45-59$ While several cases of chemical contamination of ground water were found, none was complete in its documentation. A possible case of contamination by a polyacrylamide used in EOR was discovered and monitoring is still being conducted. ${ }^{14}$ A study to examine the way in which States address the problem of ground water contamination from the injection or disposal of brine associated with oil production began this year. Time and financial constraints limit the study to examine only class II we11s (see Section 3.4.1) in two states: Kansas and Texas. ${ }^{56}$

To summarize, two general categories can be used to place the many cases of contamination reported. First there are spills in which a pollutant load is known but no monitoring was done after the surface was cleaned. Second leaching occurs over a long time period and remains undiscovered until the pollutants show up in a drinking water supply. Even if the contamination can be traced back to its source, there is rarely any idea of the amount, concentration, or duration of release. 


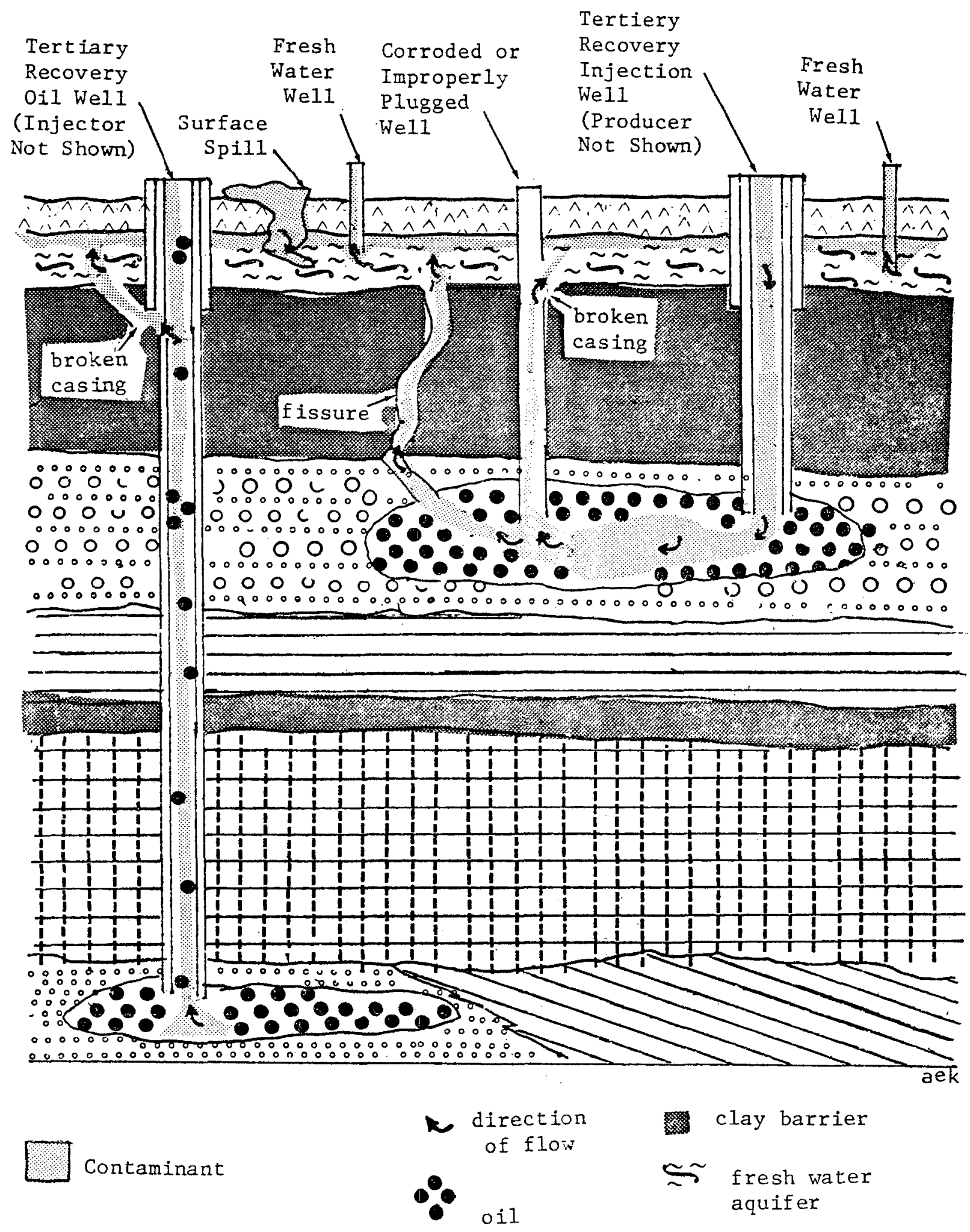

Figure 3.1. Contaminant pathways into fresh water aquifers. 


\subsubsection{Contamination from EOR Chemicals}

Aquifer contamination from oil and brine often goes undetected due to the isolation of oil fields from populated areas. Officials in several western states declared that while there are no documented cases of ground water contamination from chemical enhanced oil recovery, it was their persona1 opinion that there are cases which will be discovered when someone needs the water. $44,47,48$ In the eastern overthrust region of western Pennsylvania, New York, Ohio, and West Virginia where Pennsylvania grade crude oil has been produced for a long time there are frequently residential areas close by. Contamination of drinking water wells by brines and petroleum escaping through improperly abandoned wells is a common occurrence in these areas. ${ }^{6}$ Methane gas in the water has caused explosions in washing machines and dishwashers where electric sparks triggered the gas emitting from water faucets. ${ }^{46}$ When enhanced oil recovery methods were first proposed local citizens feared chemical contamination of their wells would follow pathways previously followed by the brines and petroleum. There is now a suspected case of polyacrylamide contamination of drinking water supplies in McKean County, Pennsylvania. Problems with precise identification of chemicals in the laboratory keeps the case listed as "suspected."14

All methods of enhanced oil recovery involve some risk to ground water. Technologies which involve the injection of chemicals into the reservoir or which fracture formations have a greater chance of an accident occurring. 60 The three general pathways of pollutant discharge into an aquifer: leaching from the surface, dispersing through imperfect wells, and dispersing through fractures in the formation, all apply as means of contamination from EOR. The risk of contamination is increased when EOR projects take place in old oil fields where unmapped abandoned wells exist. These wells are sometimes poorly sealed and lead to chemical intrusion into aquifers. The condition of old wells, which may have cracks in cement or casing due to age, corrosion, or both, can also pose risks. ${ }^{0}$ other potential risk sites can occur where fields are located in areas which have undergone significant subsidence, or which are in seismically active areas. Clearly the risks increase when reservoirs are in close proximity with aquifers or when the aquifer is near a surface disposal area. Although the Underground Injection Control (UIC) program requires monitoring of disposal wells, the possiblity of contamination from brine and EOR chemicals in produced waters still exists. Average values of polymers in produced fluids range from $20 \mathrm{pm}$ to a high of $1820 \mathrm{ppm}$. For surfactants the range is from $2 \mathrm{ppm}$ to a high of $2000 \mathrm{ppm} .17,61-79$

Recently enacted UIC regulations require strict procedures for the placement, construction, mechanical integrity, operation, and monitoring of wells. These regulations catagorize injection wells into five classes according to their use. Class I wells are industrial or municipal wells injecting waste near underground sources of drinking water. Class II wells are those used to inject waste fluids produced along with oil and gas, as well as, those wells which inject EOR chemicals. Class III wells are for injection of wastes related to mineral mining. Class IV are for the injection of hazardous wastes, and Class $V$ covers any other type, of injection we11. 
The requirements for all new Class II wells are listed in 40 CFR 146, subpart $C$, and are designed to prevent contamination from happening in the situations previously mentioned. ${ }^{80}$ While the new regulations will lessen the risk of underground pollution, certain exceptions concerning existing wells, compliance deadlines, and monitoring enforcement leave open the possibilities of future contamination. Existing Class II wells are exempt of requirements for casing and cementing as long as the wells comply with requirements existing at the time of their drilling and as long as there is no significant risk from fluids migrating into drinking water supplies. The designation of significant risk is a subjective decision to be made by the regional administrator in EPA-run UIC programs or by the state administrator in those states which have primacy. The permittee has three years to comply with the new UIC specifications during which time current practices may be continued. Although produced fluid wells must be monitored every week, wells injecting chemicals for EOR need only to be monitored monthly. Mechanical integrity has to be shown once every five years in EOR-related Class II wells. Regulations are only as good as their enforcement; the quality of enforcement of UIC regulations remains to be determined. 


\section{GROUND WATER MODELS}

\subsection{INTRODUCTION}

Ground water serves two diametrically opposite purposes: as a water source for drinking and agricultural needs, and as a medium for storing and transporting wastes. There has been a significant increase in the awareness of and concern about ground water contamination. Recognition is finally being given to the fact that ground water is a limited resource which must be protected.

Ground water models can be used to gain a better understanding of aquifer systems and to study ground water contamination problems. ${ }^{81}$ Ground water models can be grouped into three general categories: physical, electric analog, or mathematical. Physical models are constructed in a variety of shapes and generally use sand as the media. A typical example is the sand tank model. Physical models are useful but have significant problems scaling results to field level and also have limited applicability. Electric analog models, such as resistance networks and resistance-capacitance networks, were most commonly used in the 1950's and 1960's. A mathematical model is an equation or set of equations which represent a physical process or system. Depending on the specific system represented, these equations can be solved by either analytical or numerical methods.

The development of analytical models requires making many simplifying assumptions which limits the applicability of these models. Numerical models are the most general tools representing ground water systems and are solved using a computer. ${ }^{81}$ The three most commonly used numerical techniques are the finite difference method, finite element method, and the method of characteristics. An in-depth, detailed description of these methods can be easily found in the literature. The state of the art of ground water computer models and their usefulness as practical tools is discussed briefly by Prickett. 82

Before attempting to comprehend or apply ground water models one must have a through understanding of basic aquifer properties and the principles describing ground water flow. Ground water hydrology is a complex subject. There are many general textbooks in the literature which describe aquifer properties as well as illustrate the development of the equations used to describe ground water flow. $22,83-85$ Mercer and Faust provide an excellent review of the fundamental processes of interest in ground water applications. They also present a derivation and a discussion of the general equations describing ground water flow and transport, and an introductory overview of ground water modeling. ${ }^{82}$

Ground water models can be applied to a variety of situations; most commonly to model ground water flow, mass transport, heat transport, or subsidence. The physical process of ground water flow can be described by one equation. Flow models are the easiest to apply and have had the most widespread applications. Mass and heat transport models are more complex because each requires an equation in addition to the flow equation to describe the 
physical process involved. Mass transport models deal with ground water quality and are used to predict the movement and concentration of a chemical constituent in an aquifer. The heat transport equation is similar to the mass transport equation but is based on conservation of energy rather than conservation of mass. Heat transport models account for thermal effects and have had applications in areas such as geothermal energy, high level radioactive waste storage, and heat storage. Models have also been used to evaluate the impact of pumping schedules on aquifer deformation. Withdrawal of significant quantities of ground water produces compaction of the aquifer resulting in land subsidence.

Ground water models are very site and application specific. The types of models described above can be further subdivided. Variations must be made in a model in order to apply it to the unsaturated zone rather than the saturated zone. A review of ground water flow and transport models in the unsaturated zone is presented by 0ster. ${ }^{86}$ That study collected Information on 55 models and examines ten of these in detail. Fluid flows differently in fractured media than in porous media and is therefore described by a different model. Modifications must also be made to models for application to multifluid flow problems. In many applications, modelers make the assumption that chemical constituents in ground water have negligible effect on fluid density and ground water flow. This assumption is generally reasonable, however there are situations for which it is inappropriate. One example where density variations must be taken into account is the problem of saltwater intrusion.

There are a multitude of ground water models presently available. Once all the available computer codes suitable for a specific application of interest have been identified, many factors must be considered to select the one model most appropriate for the given application. For example, which physical properties and processes should be included in the model to represent adequately the ground water system of interest? What documentation exists for the computer code? Has the code been verified? What are the assumptions, limitations, and data requirenents of the code? Are there sufficient field data to meet the needs of the code? Is the code compatible with the computer system available for use? Is a listing of the code actually available? Some models are developed by private companies and these are often proprietary. As is evident from this discussion, selection of the appropriate model to use for a given class of problems can be a difficult task.

\subsection{SELECTION OF MODEL}

Several criteria were used to identify the appropriate code for this project. Either a ground water flow model and a transport model or a combined flow-transport model was needed to adequately address EOR aquifer contamination. Other criteria included a code which incorporated sufficient processes to adequately characterize the aquifer of interest, had good documentation, and was easily available. 
A limit was place on the number of models which could be considered due to time constraints on the project. Five models $15,87-90$ were selected and evaluated although more are available. The Random-Walk model developed by Prickett et al. was chosen for this project because it can be easily applied to a wide variety of ground water contamination problems. 15 It is written in generalized form and has many options which are handled through the use of subroutines. An advantage of this is that subroutines can be altered in a short period of time without significant effort and new subroutines can be easily added to test different theories of solute transport and behavior.

The Random-Walk model can simulate one- or two-dimensional, steady/ non-steady flow and solute transport problems in homogeneous or heterogeneous aquifers under water table and/or confined or semi-confined conditions. In addition, the model can evaluate the impact of time varying pumpage or injection by wells, natural or artificial recharge, water exchange between surface and ground water, the mechanism of flow from springs, and the process of ground water evapotranspiration. The model takes into account advection, dispersion, and chemical reactions. A report is available which provides good documentation and a listing of the code. ${ }^{15}$

The computer code is separable into three sections; the first for background data input, the second to address the topic of ground water flow, and the third section to handle mass transport. The code has three optional subroutines to produce head distributions which are then used to compute a velocity field. Two of these are analytical solutions and the third is a finite difference method. Other codes or actual field data could be used instead of these subroutines. The transport portion of the code is based on the idea that the distribution of the concentration of chemical constituents in ground water can be represented by the distribution of a finite number of discrete particles, where each particle represents a fraction of the total mass of the chemical constituent involved. The particles move by advection and dispersion. A particle-in-a-cell technique is used to solve the advection portion of the code. The Random-Walk model relies on the concept that, in porous media, dispersion can be considered a random process having a normal distribution and uses a random-walk technique to represent the dispersion process. 15 


\section{SURROGATE AQUIFER SITES}

\subsection{INTRODUCTION}

Surrogate site analysis creates a realistic environmental assessment whereby real data is used to analyze site-specific impacts without identifying the actual location. Surrogate sites are synthesized from real topographic, geological and hydrological data combined in such a way as to avoid reference to a specific parcel of land. By using such sites the most realistic data possible are used in numerical models, leading to more believable and understandable results. The sites for this study were chosen from the collection of States where tertiary oil production methods are used.91-117

\subsection{HYDROLOGICAL PARAMETERS}

A number of hydrological parameters are used to characterize an aquifer. They fall into two categories; the physical properties of the aquifer medium and the dynamic properties of the fluid. These parameters include hydraulic conductivity, transmissivity, storativity, porosity, bulk density, saturated thickness, and elevation of the water table.

\subsubsection{Parameters to Kstimate Physical Properties of Aquifer Medium}

The physical properties of an aquifer can be used to estimate the volume of water and the rate at which it can flow through that aquifer. Bulk density of soil is the mass of a unit volume of dry soil. Porosity is a measure of the interstitial spaces of the soil expressed as a ratio of void space to total volume. Depth to the water table and saturated thickness are can be used to determine the dimensions of the water saturated zone. Depth to the water table is defined as the distance from the land surface to the ground water table expressed as elevation above mean sea level. Saturated thickness is that part of the geologic formation through which the aquifer flows, namely, the part saturated with water.

\subsubsection{Parameters to Estimate Dynamic Properties of Fluid}

The coefficient of dispersion measures the magnitude of transport caused by dispersion. This coefficient can be estimated if the aquifer velocities and dispersivities are known. Dispersivity is defined as a characteristic mixing length which is a mathematical measurement of the spreading of the pollutant. 27 It is difficult to assign any real physical significance to dispersivity.

Hydraulic conductivity (or coefficient of permeability) is the quantity or rate of water flowing through a unit cross-sectional area of the aquifer under a unit hydraulic gradient at the prevailing water temperature. The terms hydraulic conductivity and coefficient of permeability are frequently used interchangeably and are reported in units of gallons per day per square foot. The term hydraulic conductivity will be used throughout the remainder of this report. 
The ability of an aquifer to transmit water is important in determining the quantity of water which may be drawn from it. This is expressed by the transmissivity, $T$, which is defined as the rate or amount of water flowing through a vertical strip of aquifer of unit width and extending the full saturated thickness under unit hydraulic gradient at the prevailing temperature of water. Transmissivity is often computed by multiplying the saturated thickness of the aquifer by the hydraulic conductivity.

Also of interest in determining the quantity of water which may be withdrawn is the amount of water an aquifer can store. The storage coefficient is the volume of water released from or taken into storage per unit surface area of the aquifer per change in head nornal to that surface. In a confined or artesian aquifer these dimensionless values are usually very small $\left(10^{-5}\right.$ to $\left.10^{-3}\right) .22$ In unconfined or water table aquifers the storage coefficient is equal to the specific yield, and values are normally larger $(0.05$ to $0.30) .22$ Specific yield is the ratio of the volume of water a saturated material will yield under the force of gravity to the total volume of material drained.

\subsection{AQUIFER DESCRIPTIONS}

The parameters defined in Section 5.2 vary for different aquifer types. This section will discuss three basic aquifer types: unconsolidated sand and gravel, sandstone, and fractured limestone. Each have characteristics which affect the permeability of the aquifer and the rate of transport of particles and water through the ground.

Shallow glacial deposits of unconsolidated sand, gravel, and clay are generally very porous. Transmissivities and hydraulic conductivities are large. Residence time is only decades to centuries, rather than hundreds to thousands of years. The water in such deposits is also easy to contaminate because it has recharge areas directly below the soil surface. This makes it especially susceptible to leaching and contamination from runoff.

The permeability of sandstone depends on the texture and homogeneity of the sand grains. Fine grained lenticular beds are so well packed or "tight" that there is little space for water to flow through. Lense shaped beds can also prevent water from flowing downgradient. The amount of clay mixed with the sand and the calcium or magnesium consolidating the sand affect the adsorption and precipitation of any particles in the water.

Limestone yields a good quantity of water only when it is fractured. Fractured rock often acts differently than granular porous media. When the number of fractures is large relative to the total volume of material, the flow acts in a hydrologically similar way to a sandy aquifer. If the fracture density is low, however, it becomes necessary to analyze flow in individual fractures. Flow does not follow the normal linear-laminar flow of Darcy's law particularly in wide rock fractures. Flow is anisotropic when the fracture spacing is not uniform in all directions. In addition, fractured aquifers have low porosities yet high velocities of flow. Diffusion and dispersion also act differently due to the different rock structures. ${ }^{22}$ 
These variations necessitate an alternate set of equations for modeling purposes.

Though all parameters necessary for a limestone surrogate site were gathered, such a site was not chosen. To do so would require substantial changes to the model used. These changes are possible but require more time than was available for this project. A limestone site application is left as a future goal for modeling.

\subsection{SURROGATE SITES}

An effort was made to choose surrogate sites representing different aquifer types so that a range of permeabilities and other aquifer parameters could be evaluated with regard to their effect on the transport of chemicals. It should be noted that each of these sites is based on real hydrological data, combined in such a way to avoid identification with existing EOR fields. Four sites were chosen each representing different geologic ages, rock types, and permeabilities. These sites, referenced as sites A through $\mathrm{D}$, are presented in Table 5.1 in the order in which they are used in the illustrative examples in Chapter 6. Many of the geologic and hydrologic properties are listed in in this table for each site and are based on data collected at real sites.

A discussion of each site is presented beginning with the youngest site geologically and thus the most permeable one. Site $C$ is the youngest site, from the glacial Pleistocene, consisting of unconsolidated gravel, sand, silt, and clay. Its porosity is fairly high and its transmissivity, storativity, and hydraulic conductivity are very high in comparison with the other sites. Site $A$ is an Eocene aged formation, a 37-38 million year old river delta and back-bay swamp area. It is composed of sand, sandy clay, lignite, and silt crossbedded in stratified layers. This structure influences the flow of water through the formation so that there is less pore space between grains even though the bed has a high percentage of sand. Thus the ranges for storage coefficient, transmissitivity, hydraulic conductivity, and porosity are all less than those for site C. Both sites $B$ and D are old enough for the sediments to have become compacted into sandstones. They both contain fine grain sized material with site $D$ having more clayey materials and other calcium- and magnesium-containing particles mixed through it. It is also very tightly compacted due to. Its age, 320 million years, and to the metamorphic heat and compression it has undergone. For these reasons site D has the smallest values for storage coefficient, transmissivity, hydraulic conductivity of the four sites. These four sites will be used in chapter six as the aquifers in which the hypothetical accidents occur. Specific values from the ranges reported in Table 5.1 will be chosen as input data to the model. 


\begin{tabular}{|c|c|c|c|c|}
\hline \multicolumn{5}{|c|}{$\begin{array}{l}\text { Table } 5.1 \\
\text { Surrogate Sites }\end{array}$} \\
\hline Parameter & Site A & Site B & Site C & Site D \\
\hline Geologic Age & Eocene & Permian & Pleistocene & Pennsy1vanian \\
\hline Rock type* & $\begin{array}{c}\text { sand, sandy } \\
\text { clay, lig- } \\
\text { nite, silt }\end{array}$ & $\begin{array}{l}\text { sandstone, } \\
\text { shale, } \\
\text { sandy shale }\end{array}$ & $\begin{array}{l}\text { gravel, sand } \\
\text { silt, clay }\end{array}$ & $\begin{array}{l}\text { shale, sand- } \\
\text { stone, lime- } \\
\text { stone }\end{array}$ \\
\hline Bed type & crossbedded & $\begin{array}{l}\text { lenticular, } \\
\text { massive } \\
\text { crossbedded }\end{array}$ & $\begin{array}{l}\text { unconsol- } \\
\text { idated }\end{array}$ & $\begin{array}{l}\text { tightly com- } \\
\text { pacted }\end{array}$ \\
\hline Grain size & $\begin{array}{c}\text { stratified } \\
\text { all sizes }\end{array}$ & $\begin{array}{l}\text { fine - } \\
\text { very fine }\end{array}$ & mixed & fine grained \\
\hline$\%$ Sand & 54 to 100 & 30 & NR & NR \\
\hline $\begin{array}{l}\text { Saturated } \\
\text { thickness ( } f t)\end{array}$ & 1025 & $\begin{array}{r}100-300 \\
200 \text { avg. }\end{array}$ & $65-160$ & $50-142$ \\
\hline $\begin{array}{l}\text { Depth to water } \\
\text { tablet (ft) }\end{array}$ & {$[-150]$} & $\begin{array}{l}100 \\
{[1150+]}\end{array}$ & 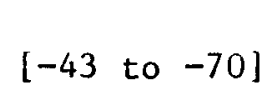 & $\begin{array}{l}15.5-147 \\
{[528+\text { to } 655+]}\end{array}$ \\
\hline Storage coef. & $\begin{aligned} 0.0001 & \text { avg. } \\
\text { up to } & 0.0002\end{aligned}$ & $\begin{array}{r}0.0001- \\
0.0003\end{array}$ & 0.0004 & 0.0000295 \\
\hline $\begin{array}{l}\text { Transmissivity } \\
(\mathrm{gpd} / \mathrm{ft})\end{array}$ & 20000 & $3000-7000$ & $50000-78000$ & $550-650$ \\
\hline $\begin{array}{l}\text { Hydraulic Con- } \\
\text { ductivity } \\
\left(g p d / \mathrm{ft}^{2}\right)\end{array}$ & $85-416$ & $20-36^{+}$ & $220-540^{+}$ & $6^{+}$ \\
\hline Porosity & $0.25-0.50$ & $0.05-0.20$ & $0.20-0.40$ & $0.05-0.25$ \\
\hline \multicolumn{5}{|c|}{$\begin{array}{l}\text { *In descending order of amount. } \\
\dagger[\text { in brackets], elevation above }(+) \text { or below }(-) \text { mean sea level. } \\
{ }_{\text {Keported as coefficient of permeability, gpd } / \mathrm{ft}^{2}} \text {. } \\
\mathrm{NR}=\text { Not reported. } \\
\mathrm{ft}=\mathrm{feet} \text {. } \\
\mathrm{gpd} / \mathrm{ft}=\text { gallons per day per foot. } \\
\mathrm{gpd} / \mathrm{ft}^{2}=\text { gallons per day per square foot. }\end{array}$} \\
\hline
\end{tabular}




\section{METHODOLOGY AND APPLICATIONS}

The objective of this study is to develop a method for modeling the transport of EOR chemicals accidentally released to fresh water aquifers. Examples involving hypothetical releases of EOR chemicals at surrogate aquifer sites are used to demonstrate one way in which this method could be applied. The examples are postulated based on typical injection rates and concentrations used at existing EOR projects. Surrogate aquifer sites are used to avoid reference to an actual parcel of land. These sites are, however, based on characteristics and properties of actual aquifers in States where chemical flooding methods are employed.

This chapter presents two separate sets of hypothetical accidents and each set consists of three examples. The first set involves polyacrylamide releases and the second involves petroleum sulfonate releases. These examples serve three purposes: to illustrate the application of this method, to indicate the type of data required to model ground water systems, and to show the interrelationships between the specific chemical, the pollutant load, the aquifer properties, and the transport of contaminants.

Al1 six examples involve a direct release of an EOR chemical into a fresh water aquifer. These examples are postulated assuming that the injection well passes through a fresh water formation above the oil reservoir, the well develops a crack, and a small percentage of the injected fluid leaks undetected directly into the aquifer for a short period of time. The wells would be monitored with a certain frequency and once a leak was discovered, injection would be discontinued until the well could be repaired. Each example is treated as a slug release by the model.

Each aquifer used in these examples is assumed to be isotropic, homogeneous, and have a uniform flow field. Generally this assumption would be the exception rather than the norm. Aquifer heterogeneities have a significant effect on the movement of contaminants and can not be neglected. We are not suggesting that a homogeneous porou's media could or should be used to represent an aquifer with heterogeneities. In fact, the model ultimately selected for this project was chosen, in part; because it could accommodate aquifer heterogeneities. The assumption of aquifer homogeneity is, however, reasonable for the objectives of thiis study.

The aquifers used in these examples correspond to those described in Section 5.4. A specific value for each aquifer property must be used in the model and these. have been selected from the ranges of values of aquifer properties and general aquifer descriptions presented in Chapter 5. Anderson discusses. many of the difticulties encountered in obtaining sufficiently detailed descriptions of an aquifer to adequately and accurately model the transport of contaminants.27 Many problems arise when attempting to determine the velocity distribution and the effects of dispersion.

Dispersion, as has been discussed previous1y, is a mixing process largely responsible for the dilution and spreading of contaminants in ground water. Experiments have shown that dispersion is proportional to ground 
water flow. Dispersion occurs along the direction of flow (longitudinal dispersion) as well as in a direction normal to the flow (transverse dispersion), but is more pronounced in the longitudinal direction.

Dispersion can be estimated if velocities and dispersivities are known. Dispersivities are even more difficult to determine than velocities. They are dependent on both the scale of the transport system and the sampling scale. Dispersivities can be measured much more easily in laboratory experiments than in the field, yet significant problems are encountered when lab results are applied to field studies. Regional longitudinal and transverse dispersivities determined from areal model studies have been tabulated and are presented in the literature. ${ }^{27}, 118$ Caution is advised in using values taken directly from the literature because dispersion coefficients are very site specific. The dispersivity data from these model studies have however provided useful trends. Typically, values of transverse dispersivity are reported to be 25 to 30 percent of the longitudinal dispersivity. 27,119 Some modelers treat dispersivities as unknowns and determine their values during calibration of their models.

It is very difficult to obtain a thorough understanding of the dispersion process due to its complex nature. As a result, ground water modelers often attempt to experimentally determine a constant value for longitudinal and transverse dispersivity for a specific site. It is recognized, however, that dispersion can vary spatially, particularly in heterogeneous ground water systems. Mathematical descriptions of dispersion are currently limited to materials that are isotropic with respect to dispersion properties of the medium. ${ }^{22}$ The process of dispersion and its mathematical representation are still sources of controversy and are currently unresolved within the research community. ${ }^{81}, 119$

The examples in this study use as many real values as are available. Mathematical models, however, require many input variables, some of which are fairly theoretical and not readily obtainable. Average values have been used, when necessary, as this approach is suitable for the objectives of this study. It is recommended that a user applying this method to a real accident would either have field tests performed to better characterize the aquifer in question, or have access to state files which might contain information enabling calculation of some of the required parameters.

\subsection{HYPOTHETICAL POLYACRYLAMIDE RELEASES}

Chapter 2 briefly describes the role of polymers in chemical EOR and their possible health effects. The adsorption properties of polyacrylamides are discussed in Chapter 3. One indication of the adsorption behavior of a chemical is the retardation factor which can be computed directly from Equation 3.4. This factor is a function of the chemical concentration as well as properties of the aquifer. Retardation factors for various polyacrylamide concentrations at aquifers with different properties have been computed and are presented in Table 6.1. Values of retardation factors used in the examples were selected from this table. 
Table 6.1

Range of Retardation Factors for Various Polyacrylamide Concentrations

\begin{tabular}{cccccc}
\hline \multirow{2}{*}{$\begin{array}{c}\text { Concentration } \\
(\mathrm{ppm})\end{array}$} & \multicolumn{3}{c}{ Sand } & & \multicolumn{2}{c}{ Sandstone } \\
\cline { 2 - 3 } \cline { 6 - 7 } & $(\mathrm{n}=0.4)$ & $(\mathrm{n}=0.3)$ & & $(\mathrm{n}=0.15)$ & $(\mathrm{n}=0.1)$ \\
\hline 100 & $6.19-17.89$ & $7.92-23.50$ & $18.19-56.94$ & $26.78-84.90$ \\
250 & $3.08-7.76$ & $3.77-10.00$ & $7.88-23.38$ & $11.31-34.56$ \\
500 & $2.04-4.38$ & $2.38-5.50$ & & $4.44-12.19$ & $6.16-17.78$ \\
750 & $1.69-3.25$ & $1.92-4.00$ & & $3.29-8.45$ & $4.43-12.17$ \\
1000 & $1.52-2.69$ & $1.69-3.25$ & & $2.72-6.59$ & $3.58-9.39$ \\
1500 & $1.35-2.13$ & $1.46-2.50$ & & $2.15-4.73$ & $2.72-6.59$ \\
2000 & $1.26-1.84$ & $1.35-2.13$ & & $1.86-3.80$ & $2.29-5.20$ \\
2500 & $1.21-1.68$ & $1.28-1.90$ & & $1.69-3.24$ & $2.03-4.36$ \\
3000 & $1.17-1.56$ & $1.23-1.75$ & & $1.57-2.86$ & $1.86-3.80$ \\
3500 & $1.15-1.48$ & $1.20-1.64$ & & $1.49-2.60$ & $1.74-3.39$ \\
4000 & $1.13-1.42$ & $1.17-1.56$ & & $1.43-2.40$ & $1.65-3.10$ \\
4500 & $1.12-1.38$ & $1.15-1.50$ & & $1.38-2.24$ & $1.57-2.86$ \\
5000 & $1.10-1.34$ & $1.14-1.45$ & & $1.34-2.12$ & $1.52-2.68$ \\
\hline
\end{tabular}

Note: $\mathrm{n}=$ porosity.

Three hypothetical accidents involving polyacrylamides are presented. These examples have been postulated to simulate real field situations. Enhanced Recovery Week (ERW), Oil and Gas Journal (OGJ), and Department of Energy (DOE) EOR technical project reports were reviewed to obtain typical injection rates and concentrations of polyacrylamides at current or proposed polymer flood projects. Injection rates of polyacrylamides typically range from 265 to 3000 barrels per day (bb1/d) per well. Many EOR projects inject a tapered polyacrylamide sluy, and reported values of concentration range from 6000 to $100 \mathrm{ppm}$.

The first example presented involves a release of polyacrylamides, with a concentration from the lower end of the reported range of values, into a fresh water sand aquifer. The second example examines the effect of a significant increase in pollutant loading on the same aquifer. The third example involves the release of the pollutant load from the second example to a sandstone aquifer rather than a sand aquifer. This illustrates the effect aquifer properties can have on contaminant transport. The chemical data, aquifer data, and model grid data for the three hypothetical polyacrylamide examples are presented in Table 6.2.

\subsubsection{Examp1e 1}

This example is based on a hypothetical polyacrylamide injection rate of $900 \mathrm{bb} 1 / \mathrm{d}$ at a concentration of $1000 \mathrm{ppm}$. It is assumed that ten percent of the injected fluid leaks undetected for a period of 15 days into a fresh water aquifer. 


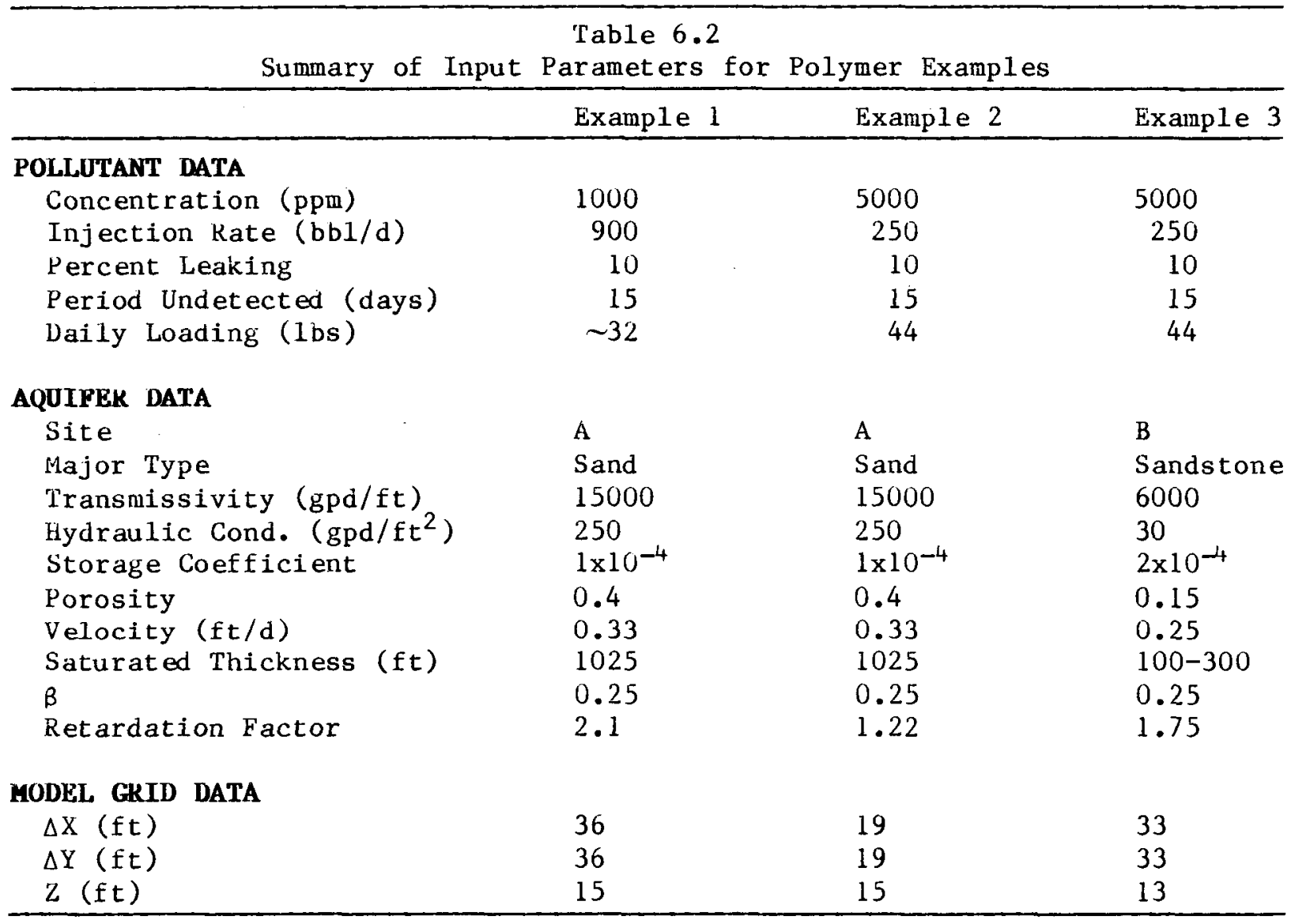

Note: $\beta$ is the ratio of the transverse dispersivity to the longitudinal dispersivity.

$\mathrm{Z}$ is the vertical mixing zone of the contaminant within the saturated thickness of the aquifer.

The fresh water aquifer, site $A$, is assumed to be an isotropic, homogeneous sand formation with a uniform flow of four inches per day. The concentration of polyacrylamides resulting from this hypothetical release into aquifer site $A$ has been calculated for three different time periods and the results are shown in Figure 6.1. One year after this accident the peak concentration, approximately $400 \mathrm{ppm}$, is 110 feet directly downgradient from the injection well. The plume has spread out 70 feet longitudinally and 35 feet transversely on either side of the maximum concentration point. Four years after the initial accident, the estimated peak concentration has decreased to $125 \mathrm{ppm}$ and has traveled 260 feet from the injection we11. The calculations for the last time period, eight years after the release, show the maximum concentration is approximately $70 \mathrm{ppm}$ and is located 500 feet directly downgradient of the point of entry. The slug has a total longitudinal length of 400 feet and transverse length of 200 feet at this time. 


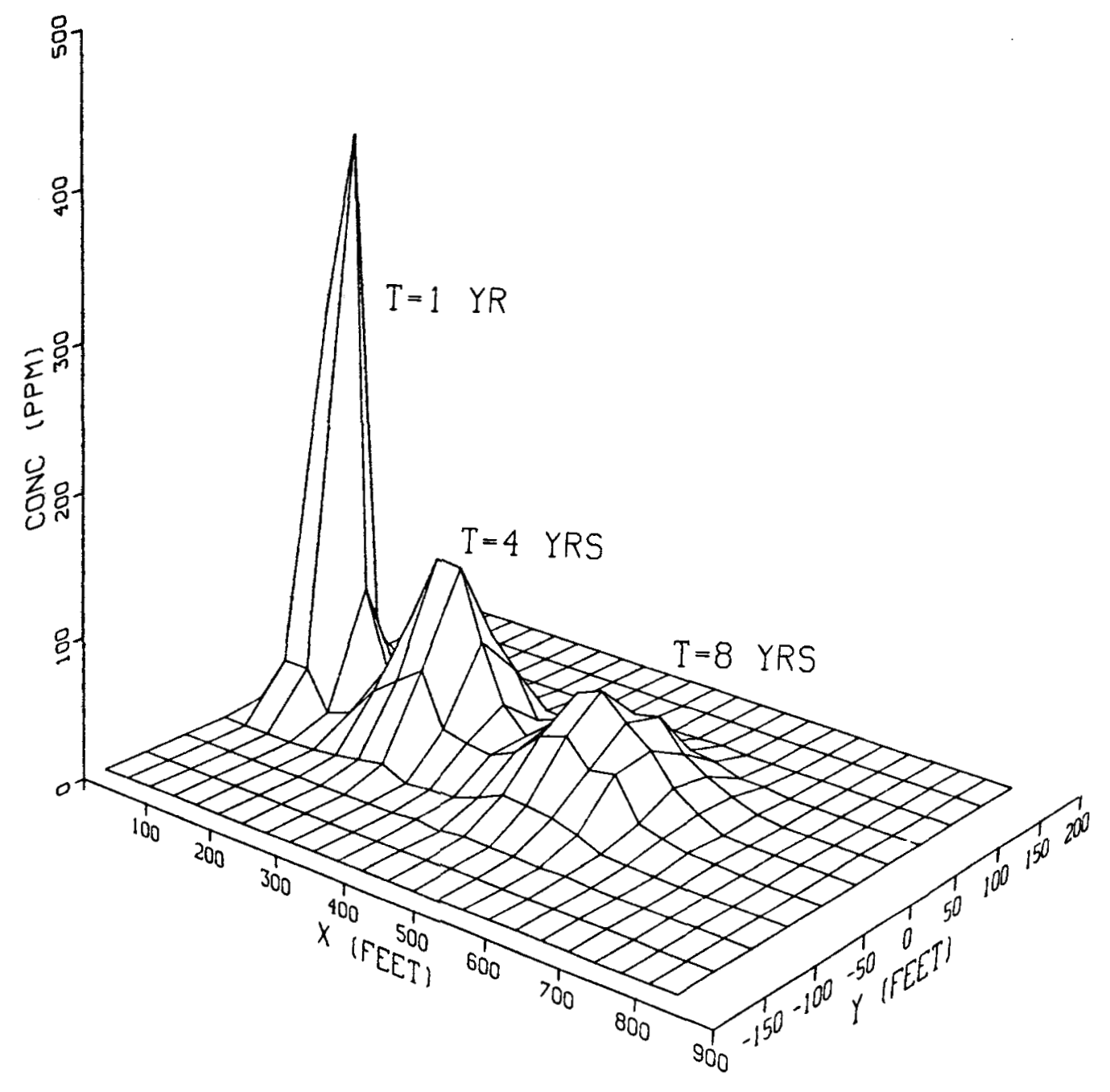

Figure 6.1. Concentration of polyacrylamides from example 1 at aquifer site A for three time periods.

\subsubsection{Exanple 2}

This example evaluates the impact of a larger daily pollutant load that occurs for the same duration at the location used in example 1 (aquifer site A). This accident is assumed to occur at an injection well where $250 \mathrm{bbl} / \mathrm{d}$ of polyacrylamides are being injected with a concentration of $5000 \mathrm{ppm}$. It is assumed that ten percent of the injected fluid leaks undetected for a period of 15 days. "The resulting daily pollutant loading represents a $40 \%$ increase in dally loading compared to the previous example.

The concentration of polyacrylamides at aquifer site $A$ from this accidental release has been calculated for the same time periods as example 1. Figure 6.2 shows the results. The estimated maximum concentration of polyacrylamides one year after the initial leak is $635 \mathrm{ppm}$ at a location 115 feet directly downgradient of the injection well. At this point, the slug has a 


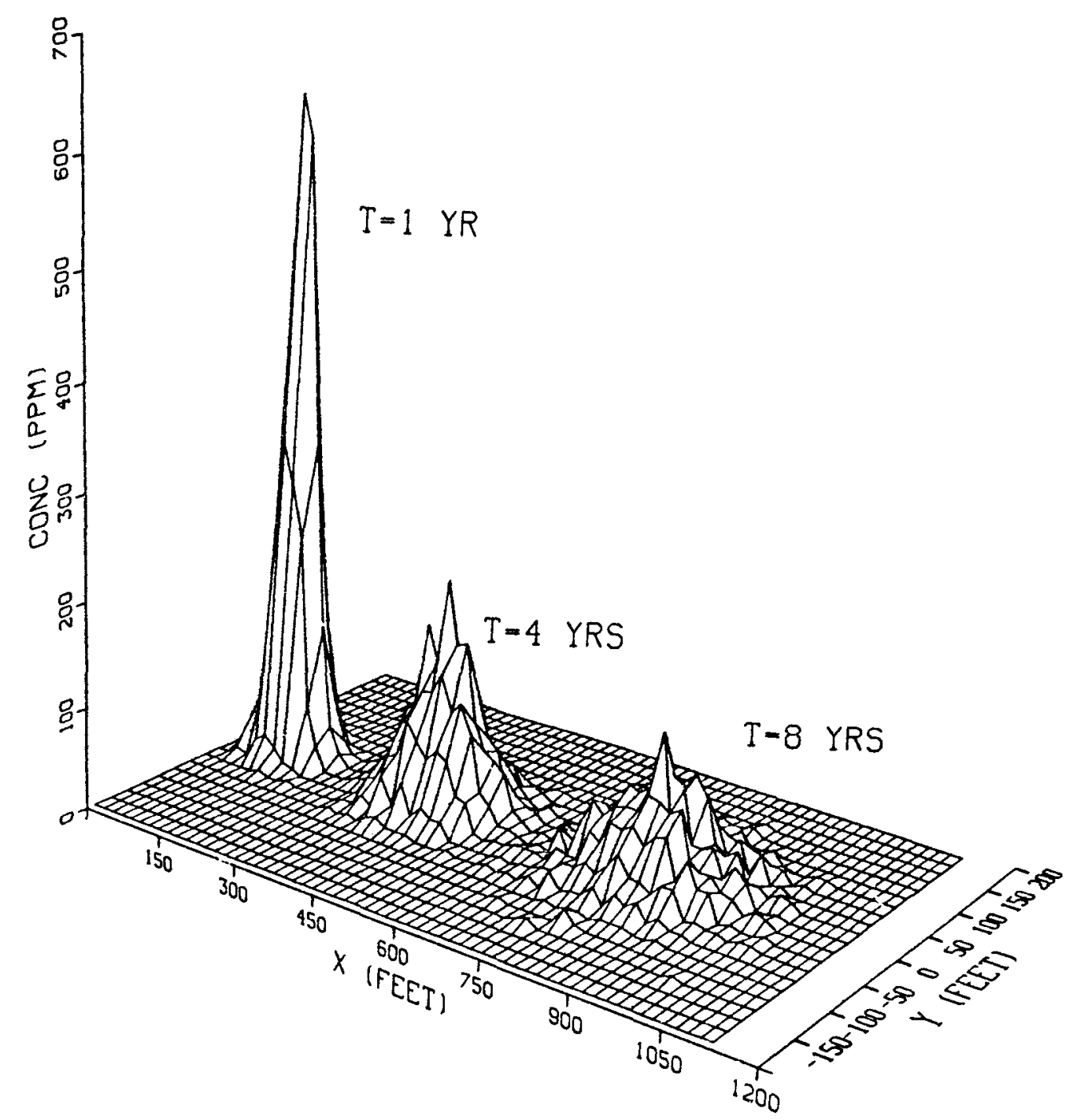

Figure 6.2. Concentration of polyacrylamides from example 2 at aquifer site A for three time periods.

maximum longitudinal length of 150 feet and transverse length of approximately 70 feet. Four years after the accident occurred, the estimated peak concentration was $220 \mathrm{ppn}$ at a distance of 420 feet from the leak. Eight years after the release, the maximum concentration is estimated to decrease to 135 ppm and would be located 800 feet from the point of entry. By this time period, the plume is estimated to spread 210 feet along the gradient and 115 feet in a transverse direction on either side of the location of maximum concentration.

\subsubsection{Example 3}

This example indicates the role aquifer properties play in the transport of contaminants by evaluating the same accident described in example 2 at a 


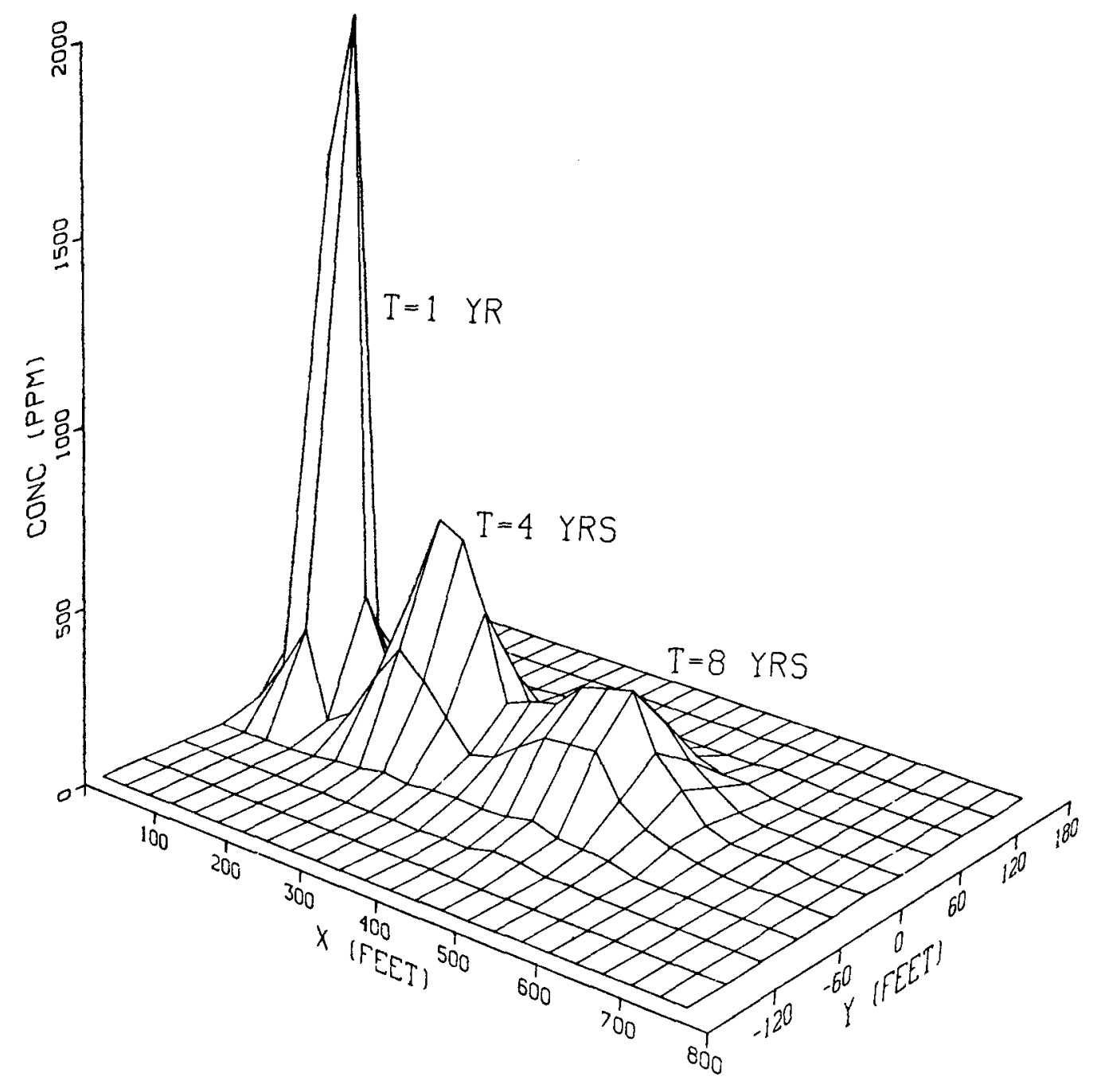

Figure 6.3. Concentration of polyacrylamides from example 3 at aquifer site $B$ for three time periods.

different aquifer (site B). The same daily pollutant loading is used, but this aquifer is a tight sandstone formation rather than sand, and has significantly lower values of transmissivity, hydraulic conductivity, porosity, and ground water flow. In addition, the retardation factor is much larger than the one in example 2 due to the different aquifer characteristics.

The concentration of polyacrylamides at aquifer site $B$ has been calculated for the same three time periods as in the previous examples; results are shown in Figure 6.3. One year after this hypothetical release, the concentration of polyacrylamides is estimated to be $1,970 \mathrm{ppm}$ at a location 100 feet directly downgradient of the leak. At this time period, the slug has dispersed approximately 65 feet longitudinally and 33 feet transversely on either side of the point of maximum concentration. At the second time period, four years after the release, the estimated peak concentration is $645 \mathrm{ppm}$ 
and is expected to travel 230 feet from the injection well. The maximum concentration eight years after the initial leak is estimated to be $340 \mathrm{ppm}$ at a distance 480 feet from the point of entry. The plume has a total longitudinal length of 400 feet and transverse length of 200 feet.

\subsubsection{Summary of Polyacrylamide Examples}

Three accidents have been postulated concerning ground water contamination from EOR injection wells leaking polyacrylamides. A comparison of examples 1 and 2 shows the effect chemical concentration has on contaminant transport by evaluating two accidental releases of different polyacrylamide concentrations at the same site. The most obvious result from Figures 6.1 and 6.2 is that it takes longer to reduce the polyacrylamide concentration from the second accident. In addition, the plume from the second example advances further in the same time than the plume from the first accident does. These results are due to the higher concentration used in example 2. Both plumes have approximately the same areal spread, as one would expect, because these accidents were assumed to occur in the same aquifer.

Examples 2 and 3 evaluate the effect of an identical accident occurring at different fresh water formations. It takes much longer for the polyacrylamide concentration to decrease from the third example than the second example even though both assumed the same initial concentration. In addition, the plume from the third accident advances much more slowly and has a slightly smaller areal spread than the plume from the second accident. The differences in aquifer properties are directly responsible for these results. The aquifer at the site of the third example has lower values of velocity, porosity, transmissivity, hydraulic conductivity, and dispersivities. In addition, the computed value for the retardation factor is larger because of these aquifer properties.

The results of these hypothetical accidents are summarized, including the maximum concentration and its location at specified time periods after the release as well as the overall size of the plume, and are presented in Table 6.3.

Table 6.3

Summary of Plume Descriptions for Polymer Examples

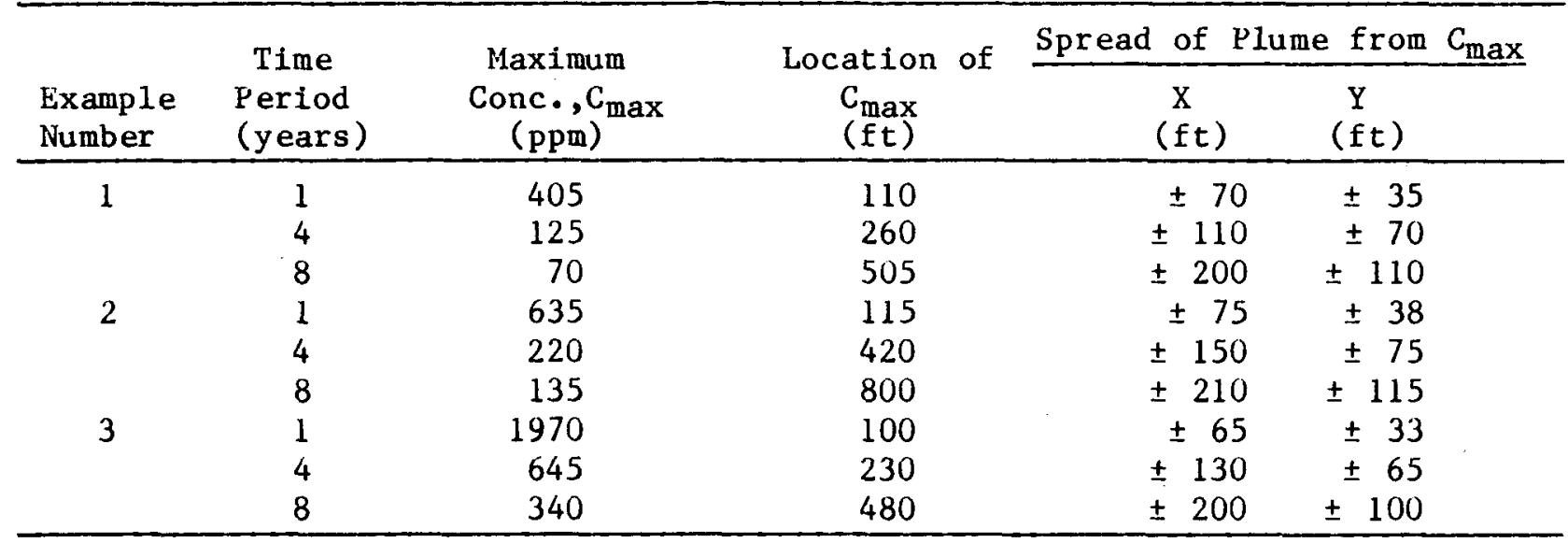




\subsection{HYPOTHETICAL PETROLEUM SULFONATE RELEASES}

Three hypothetical accidents involving petroleam sulfonates have been postulated using the identical assumptions relating to the conditions of release as the polyacrylamide examples described in Section 6.1. The micellar polymer process is still experimental, as well as quite expensive and it is expected that these injection wells will be monitored frequently. Therefore, the undetected leak period in these examples has been assumed to be ten days.

The potential health effects of some surfactants are described in Chapter 2 and their adsorption properties are discussed in Chapter 3. Retardation factors for various petroleum sulfonate concentrations have been computed at two different aquifers based on the adsorption data presented in Chapter 3 and are presented in Table 6.4. Values of retardation factors used in the petroleum sulfonate examples were selected from this table.

The examples of contamination from petroleum sulfonates are postulated to simulate real field conditions by using typical concentrations and injection rates at current or proposed surfactant projects. This information was obtained by reviewing ERW, OGJ, and DOE EOR technical project reports. As discussed in Chapter 2, surfactant floods are generally performed in one of two ways; either low concentrations of surfactants are injected in large volumes or high concentrations are injected in much smaller volumes. The first procedure usually uses surfactants in concentrations ranging from 10,000 to $30,000 \mathrm{ppm}$ while the second method generally uses concentrations ranging from 50,000 to $100,000 \mathrm{ppm}$. Although each surfactant flood project is designed for a specific application, typical ranges of injection rates are 100 to $1000 \mathrm{bbl} / \mathrm{d}$.

Tab1e 6.4

Range of Ketardation Factors for Various Petroleum Sulfonate Concentrations

\begin{tabular}{cccccc}
\hline \multirow{2}{*}{$\begin{array}{c}\text { Concentration } \\
(\mathrm{ppm})\end{array}$} & \multicolumn{2}{c}{ Sand } & \multicolumn{2}{c}{ Sandstone } \\
\cline { 2 - 3 } \cline { 5 - 6 } & $(\mathrm{n}=0.4)$ & $(\mathrm{n}=0.3)$ & $(\mathrm{n}=0.15)$ & $(\mathrm{n}=0.10)$ \\
\hline 10,000 & $1.263-2.313$ & $1.350-2.750$ & $1.83-5.13$ & $2.24-7.20$ \\
12,000 & $1.219-2.094$ & $1.292-2.458$ & $1.69-4.44$ & $2.03-6.17$ \\
15,000 & $1.175-1.875$ & $1.233-2.167$ & $1.55-3.76$ & $1.83-5.13$ \\
17,000 & $1.154-1.772$ & $1.206-2.029$ & $1.49-3.43$ & $1.73-4.65$ \\
20,000 & $1.131-1.656$ & $1.175-1.875$ & $1.41-3.07$ & $1.62-4.10$ \\
25,000 & $1.105-1.525$ & $1.140-1.700$ & $1.33-2.65$ & $1.50-3.48$ \\
30,000 & $1.088-1.438$ & $1.117-1.583$ & $1.28-2.38$ & $1.41-3.07$ \\
50,000 & $1.053-1.263$ & $1.070-1.350$ & $1.17-1.83$ & $1.25-2.24$ \\
60,000 & $1.044-1.219$ & $1.058-1.292$ & $1.14-1.69$ & $1.21-2.03$ \\
70,000 & $1.038-1.188$ & $1.050-1.250$ & $1.12-1.59$ & $1.18-1.89$ \\
80,000 & $1.033-1.164$ & $1.044-1.219$ & $1.10-1.52$ & $1.16-1.78$ \\
90,000 & $1.029-1.146$ & $1.039-1.194$ & $1.09-1.46$ & $1.14-1.69$ \\
100,000 & $1.026-1.131$ & $1.035-1.175$ & $1.08-1.41$ & $1.12-1.62$ \\
\hline
\end{tabular}

Note: $\mathbf{n}=$ porosity. 
The first example of ground water contamination froin petroleum sulfonate examines the effect of an accident occurring during the injection of a low concentration of surfactants at a sand aquifer. The second petroleum sulfonate example evaluates the effect of the same pollutant load leaking into a fresh water sandstone aquifer. The third example in this set is assumed to occur at the same sandstone aquifer but involves an accidental release of a high concentration of petroleum sulfonate. A summary of the chemical data, aquifer data, and model grid data for these cases is presented in Table 6.5

\subsubsection{Example 4}

This example is based on an accident occurring during a low concentration, large volume surfactant flood where petroleum sulfonates are injected at a rate of $250 \mathrm{bbl} / \mathrm{d}$ with a concentration of $20,000 \mathrm{ppm}$. It is assumed that the injection well develops a small crack and five percent of the injected fluid leaks directly into a fresh water aquifer undetected for a period of ten days. The aquifer used in this example corresponds to aquifer site $C$ described in Chapter 5. It is assumed that this aquifer is homogeneous and has a uniform velocity of three inches per day.

The concentration of petroleum sulfonates resulting from this hypothetical release has been calculated for the same three time periods as the polyacrylamide examples and the results are shown in Figure 6.4. One year after this accident, the maximum concentration of petroleum sulfonates is estimated to be $4230 \mathrm{ppm}$ and located 80 feet directly downgradient of the injection well. The plume is expected to disperse 45 feet longitudinally and approxinately 15 feet transversely on either side of the maximum concentration point. At the second time period, four years after the leak, the estimated peak concentration has decreased to $1460 \mathrm{ppm}$ and has traveled 240 feet. Eight years after the accident, the maximum concentration is estimated to be 715 ppm 455 feet directly downgradient of the point of entry. At this time, the plume is expected to spread 130 feet longitudinally and 65 feet transversely on either side of the location of the maximum concentration.

\subsubsection{Bxample 5}

The second surfactant case, example 5, evaluates an accident identical to that in example 4 occurring at a significantly different fresh water aquifer. This aquifer corresponds to aquifer site $D$ and is assumed to be homogeneous with a uniform velocity of two inches per day. As shown in Table 6.5, aquifer site $D$ has significantly lower values of transmissivity, hydraulic conductivity and porosity as compared to aquifer site C. One additional significant difference in these two examples is in the value of the retardation factor which is due to the different aquifer types.

Figure 6.5 illustrates the distribution of petroleum sulfonates in aquifer site $D$ one year after this accident. The maximum concentration is estimated to be $15,100 \mathrm{ppm}$ approximately 55 feet from the injection well. The slug is expected to disperse 25 to 30 feet both longitudinally and transversely on either side of the maximum concentration point. The concentration of petroleum sulfonates four years after the hypothetical release is shown in 


\begin{tabular}{|c|c|c|c|}
\hline Summary of Input & $\begin{array}{r}\text { Table } 6.5 \\
\text { Parameters for }\end{array}$ & Surfactant Examples & \\
\hline & Example 4 & Example 5 & Example 6 \\
\hline \multicolumn{4}{|l|}{ POLLUTANT DATA } \\
\hline Concentration (ppm) & 20000 & 20000 & 50000 \\
\hline Injection Rate (bbl/d) & 250 & 250 & 200 \\
\hline Percent Leaking & 5 & 5 & 5 \\
\hline Period Undetected (days) & 10 & 10 & 10 \\
\hline Daily Loading (1bs) & 88 & 88 & 175.5 \\
\hline \multicolumn{4}{|l|}{ AOUIFER DATA } \\
\hline Site & $\mathrm{C}$ & $\mathrm{D}$ & $\mathrm{D}$ \\
\hline Major Type & Sand & Sands tone & Sandstone \\
\hline Transmissivity (gpd/ft) & 50000 & 600 & 600 \\
\hline $\begin{array}{l}\left.\text { Hydraulic Cond. (gpd/ft }{ }^{2}\right) \\
\text { Storage Coefficient }\end{array}$ & $\begin{array}{l}400 \\
4 \times 10^{-4}\end{array}$ & $\begin{array}{l}6 \\
3 \times 10^{-5}\end{array}$ & $\begin{array}{l}6 \\
3 \times 10^{-5}\end{array}$ \\
\hline Porosity & 0.3 & 0.1 & 0.1 \\
\hline Velocity ( $f t / d)$ & 0.25 & 0.167 & 0.167 \\
\hline Saturated Thickness ( $f t$ ) & $65-160$ & $50-142$ & $50-142$ \\
\hline B & 0.25 & 0.25 & 0.25 \\
\hline Retardation Factor & 1.6 & 2.9 & 1.8 \\
\hline \multicolumn{4}{|l|}{ MODEL GRID DATA } \\
\hline$\Delta X(f t)$ & 10 & 28 & 25 \\
\hline$\Delta Y(f t)$ & 16 & 28 & 25 \\
\hline$z(f t)$ & 10 & 9 & 9 \\
\hline
\end{tabular}

Note: $\beta$ is the ratio of the transverse dispersivity to the longitudinal dispersivity.

$\mathrm{Z}$ is the vertical mixing zone of the contaminant within the saturated thickness of the aquifer.

Figure 6.6. The peak concentration at this time is estimated to be $7,470 \mathrm{ppm}$ and located approximately 110 feet directly downgradient froin the point of entry. Eight years after the incident, the maximum concentration is estimated to decrease to $4070 \mathrm{ppm}$ and have traveled 200 feet from the injection well (Figure 6.7). At this time, the plume is estimated to spread 110 feet longitudinally and 55 feet transversely on either side of the location of the maximum concentration.

\subsubsection{Examp1e 6}

This example evaluates the impact of an accident occurring during the injection of a high concentration of surfactants at aquifer site $D$. The hypothetical release is assumed to occur at an injection well where $200 \mathrm{bbl} / \mathrm{d}$ of petroleum sulfonates are being injected with a concentration of 50,000 $\mathrm{ppm}$. It is assumed that five percent of the injected fluid leaks undetected for a period of ten days. This daily pollutant loading is approximately 


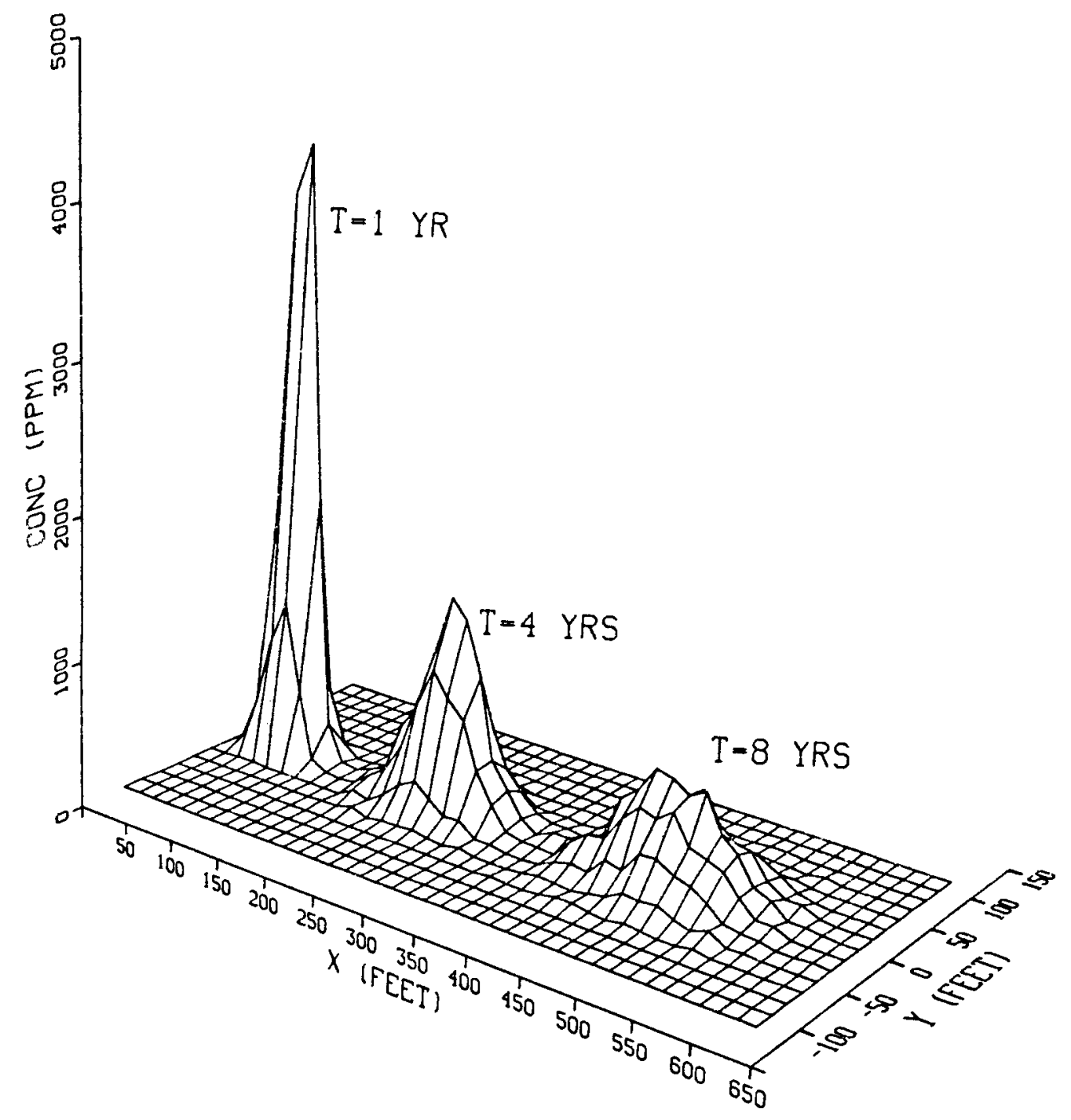

Figure 6.4. Concentration of petroleum sulfonates from example 4 at aquifer site $C$ for three time periods. 


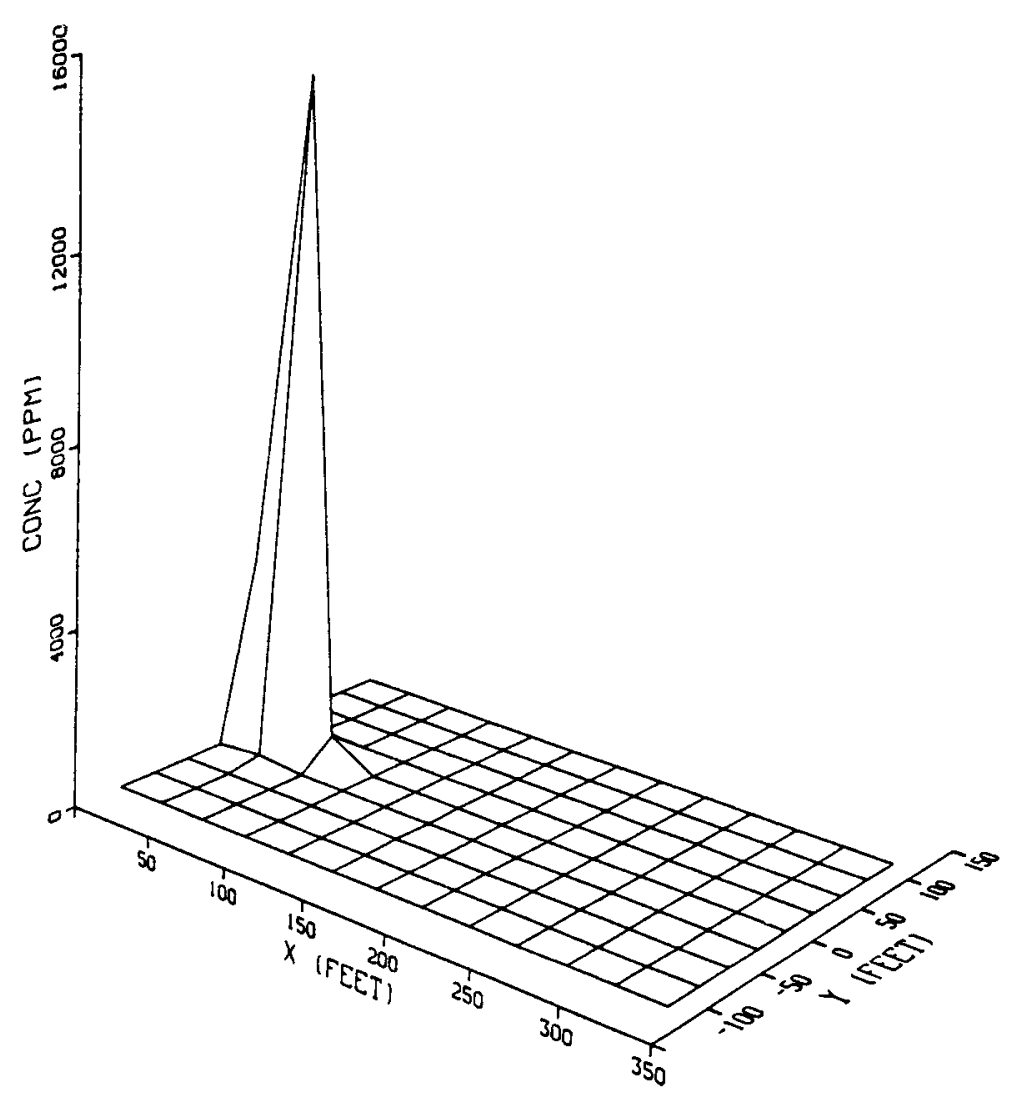

Figure 6.5. Concentration of petroleum sulfonates from example 5 at aquifer site $D$ one year after the release.

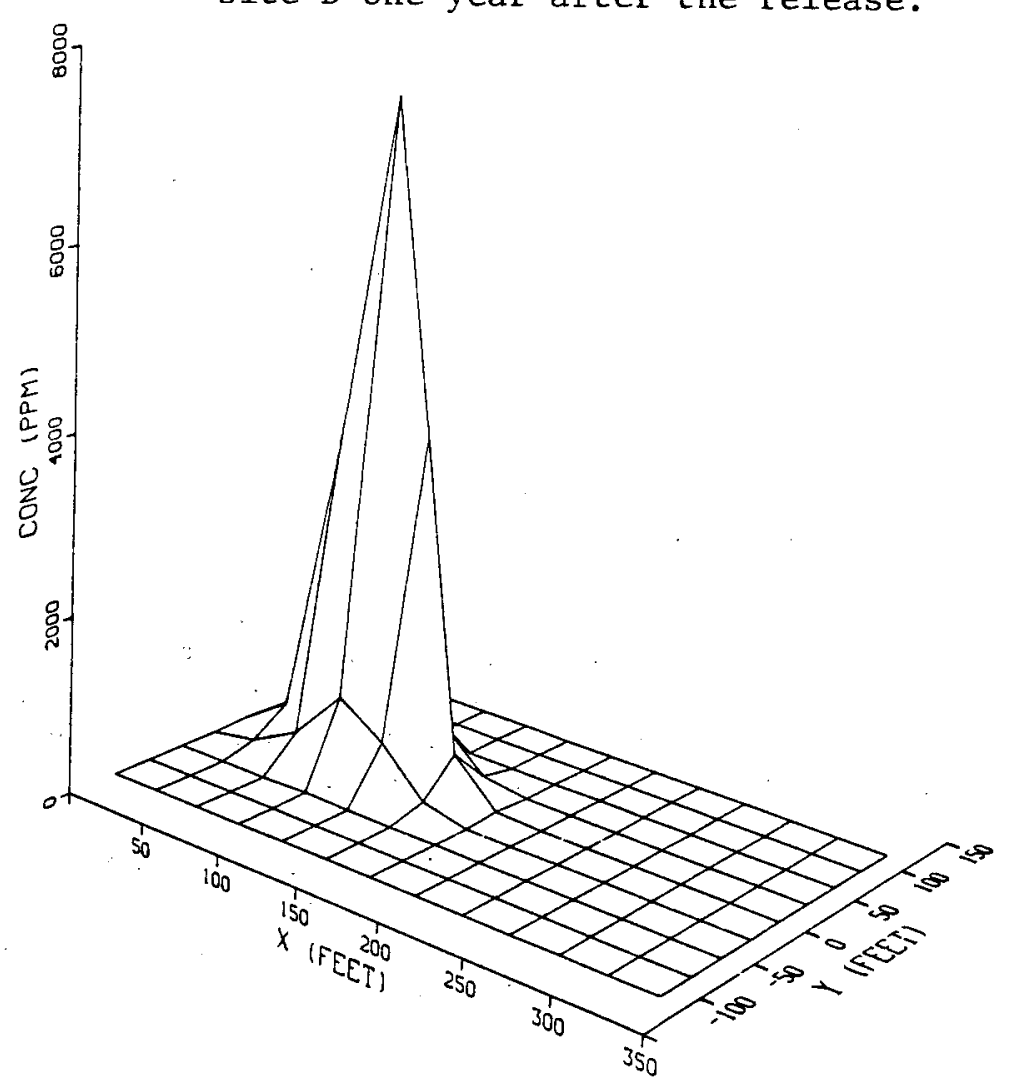

Figure 6.6. Concentration of petroleum sulfonates from example 5 at aquifer site $D$ four years after the release. 


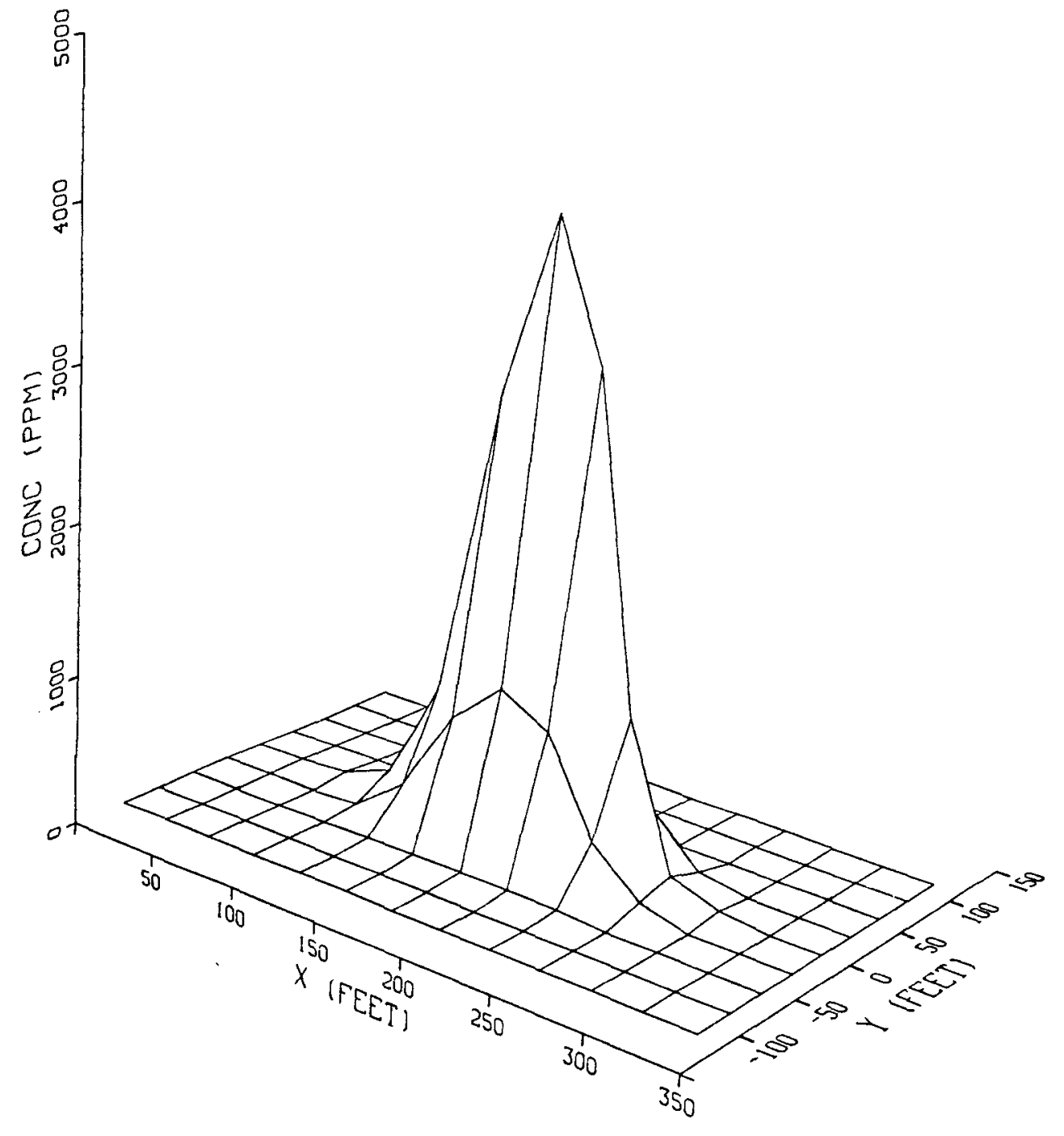

Figure 6.7. Concentration of petroleum sulfonates from example 5 at aquifer site D eight years after the release.

double the daily loading of the previous example. It is also important to note that in addition to a different daily loading, the retardation factor used in example 6 is much smaller than that in example 5. This is due to the different concentrations involved in these two accidents.

The concentration of petroleum sulfonate at aquifer site $D$ one year after this hypothetical release is shown in figure 6.8. The estimated maximum concentration of petroleum sulfonate is $25,000 \mathrm{ppm}$ at a location 60 feet directly downgradient of the injection well. The plume is estimated to spread 35 to 40 feet longitudinally and 25 feet transversely on either side of the maximum concentration point. Four years after the initial accident, the estimated peak concentration has decreased to $10,000 \mathrm{ppm}$ and has traveled 160 to 165 feet from the point of entry (Figure 6.9). Figure 6.10 shows the 
anticipated concentration distribution eight years after the release. The maximum concentration is estimated to be $5260 \mathrm{ppm}$ and located 300 feet directly downgradient of the injection well. The plume is estimated to spread 125 feet longitudinally and 50 feet transversely on either side of the maximum concentration point at this time.

\subsubsection{Summary of Petroleum Sulfonate Examples}

Three hypothetical accidents, each involving a direct release of petroleum sulfonates into a fresh water aquifer, are presented. These accidents are postulated to simulate real field conditions and are assumed to occur during normal EOR operations. A comparison of examples 4 and 5 shows the impact of an identical accident occurring at two distinct fresh water aquifers. At the same points in time, the concentration of petroleum sulfonates is much larger from example 5 than example 4 even though both accidents assumed identical initial injection concentrations. The plume from example 5 advances much more slowly and has a slightly smaller areal spread than the plume from example 4. These results are due to the differences in aquifer properties and to the much larger retardation factor calculated for example 5.

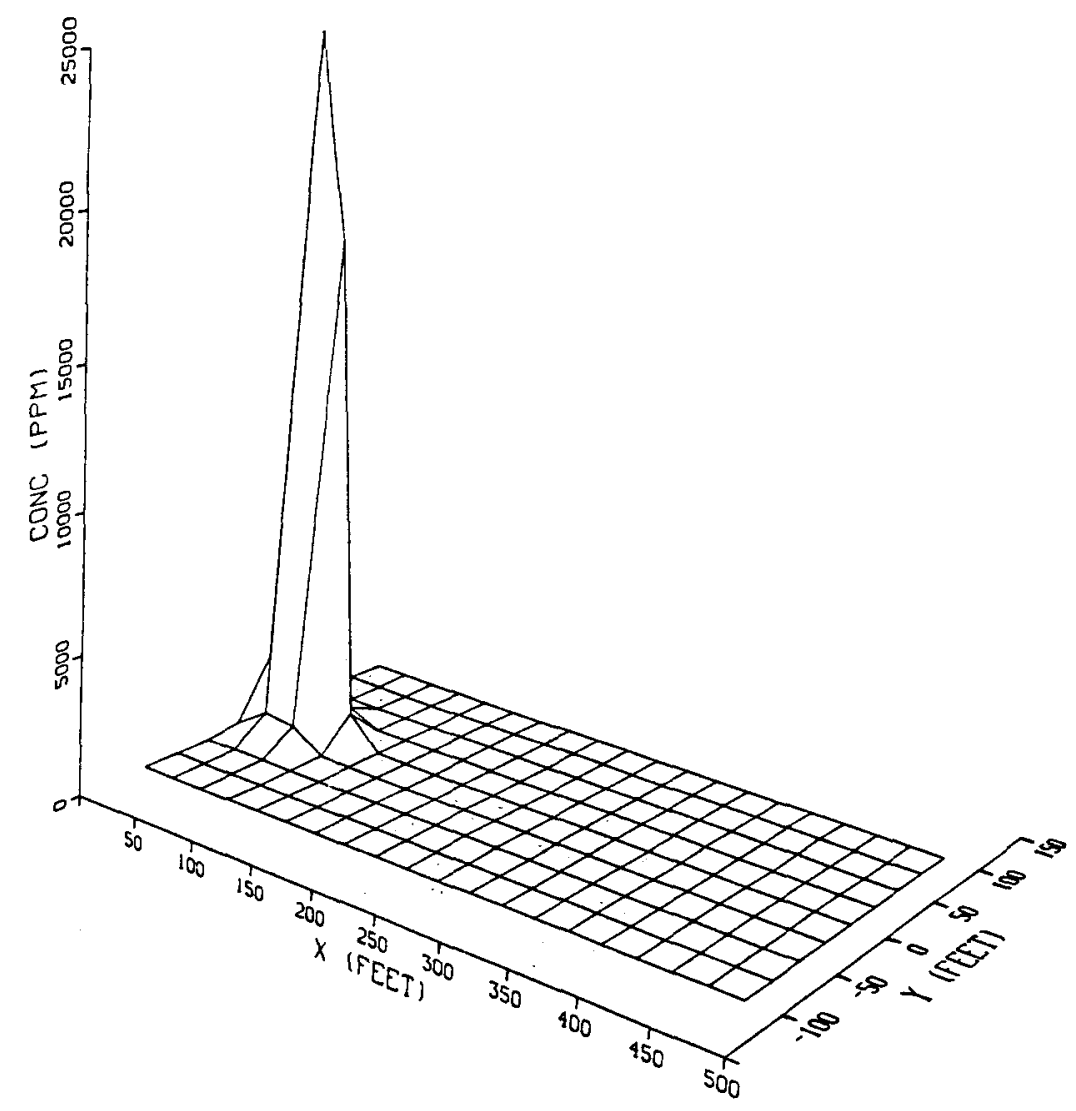

Figure 6.8. Concentration of petroleum sulfonates from example 6 at aquifer site $D$ one year after release. 


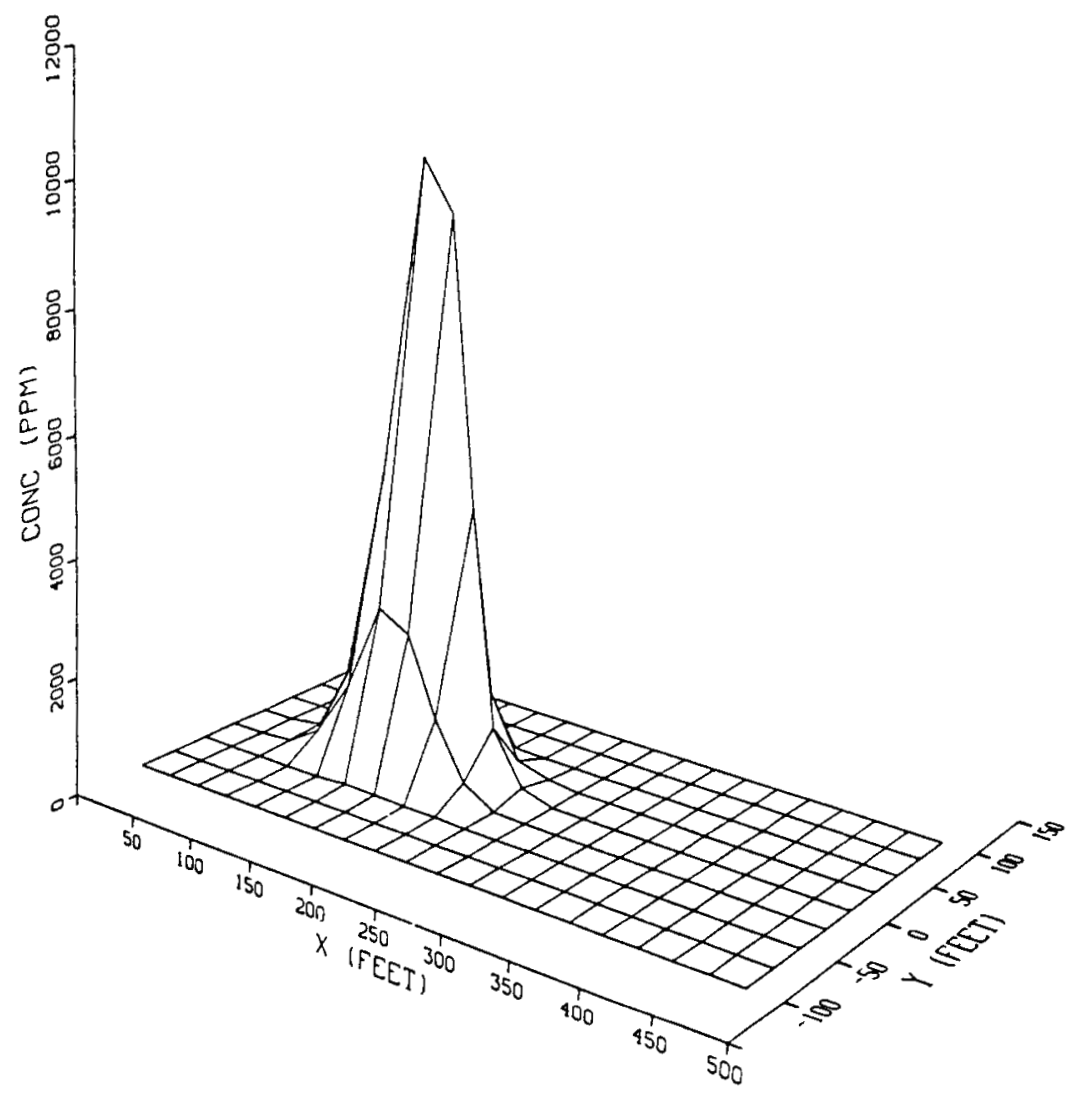

Figure 6.9. Concentration of petroleum sulfonates from example 6 at aquifer site $D$ four years after release.

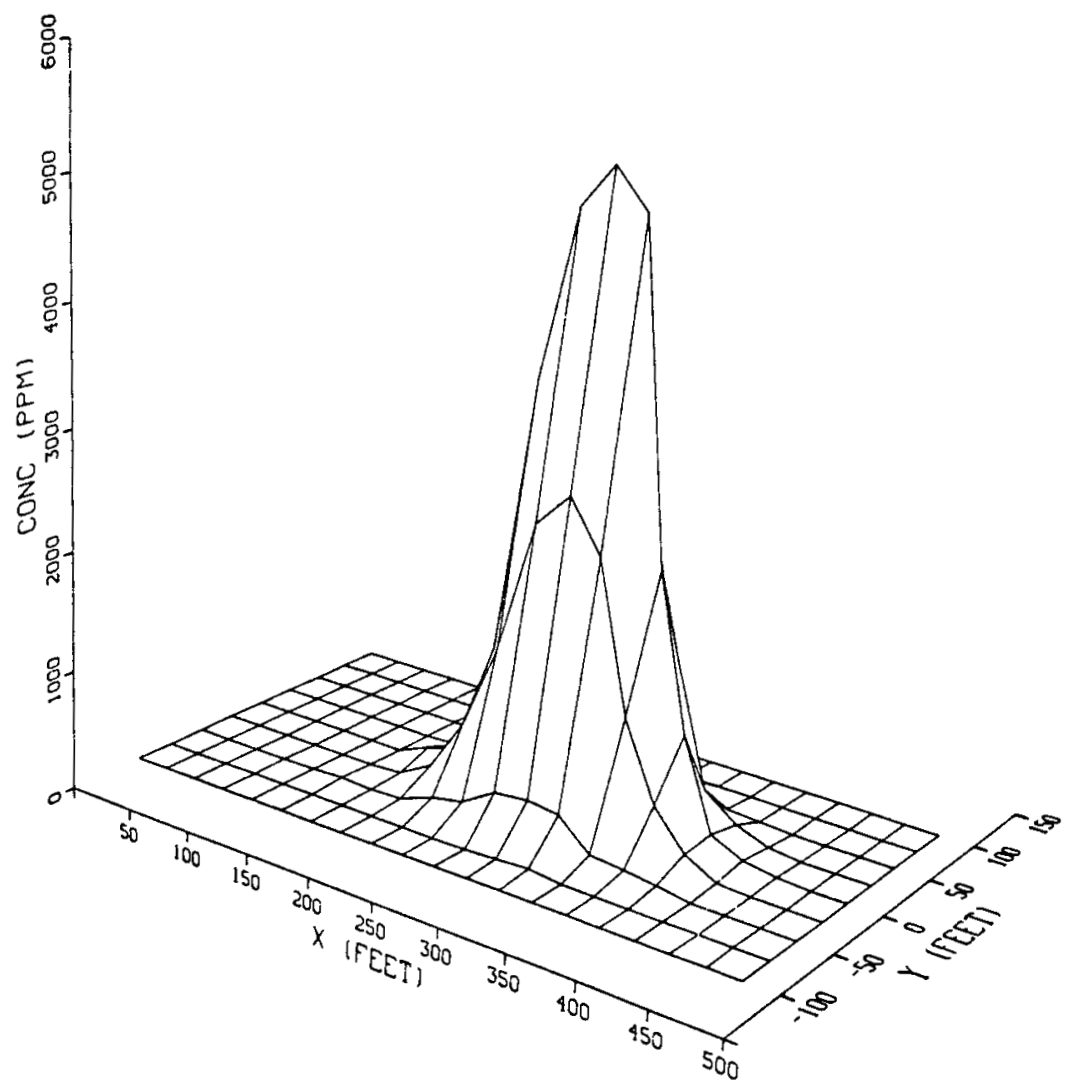

Figure 6.10. Concentration of petroleum sulfonates from example 6 at aquifer site $D$ eight years after release. 
Examples 5 and 6 evaluate the impact of two releases involving different concentrations of petroleum sulfonates at the same aquifer. It takes much longer for the petroleum sulfonate concentration to decrease from the sixth example than from the fifth example. The plume from the sixth example advances further and has a slightly larger areal spread at the same points in time after the hypothetical releases than the plume from the fifth example. These results are due to the significantly different values of concentrations and retardation factors used in these hypothetical accidents.

The results of these hypothetical accidents are summarized, including the maximum concentrations and their location at specified time periods after the release as well as the overall sizes of the plumes, and are presented in Table 6.6.

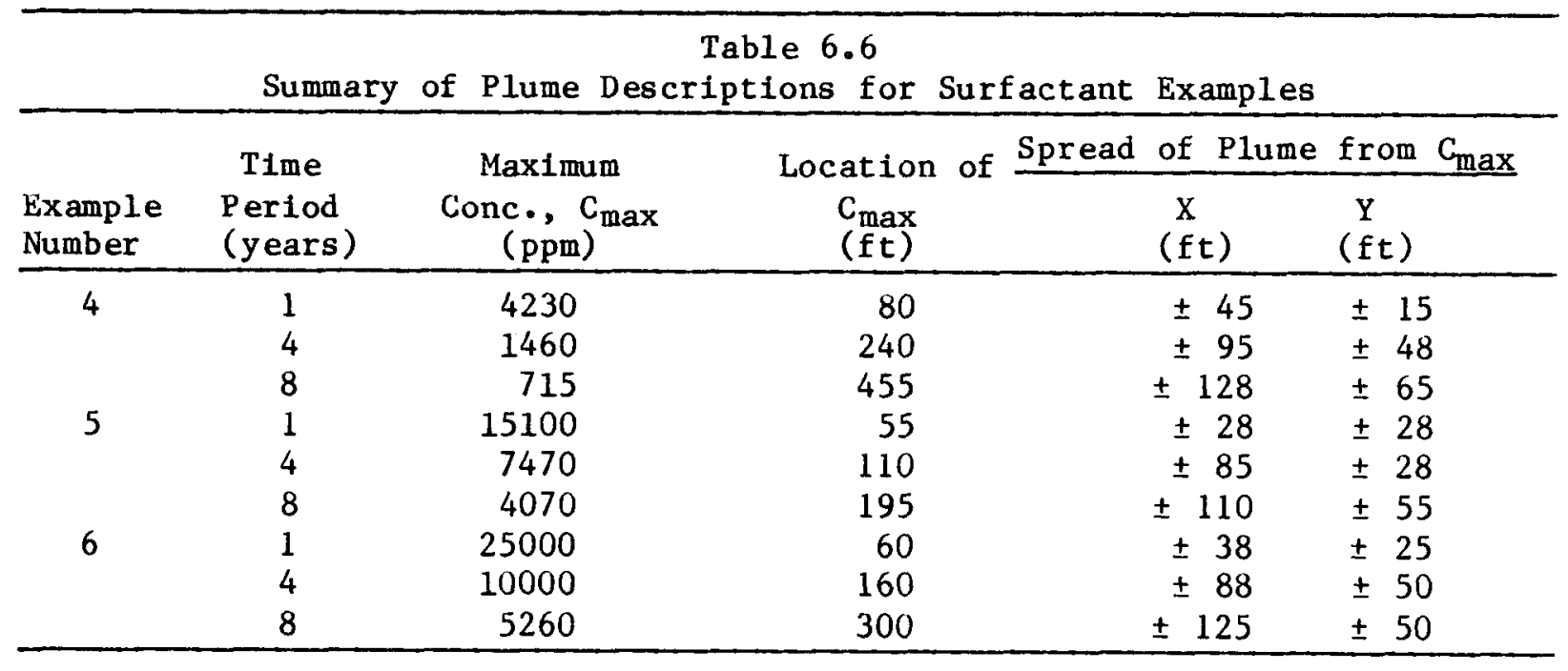




\section{SUMMARY AND CONCLUSIONS}

The objective of this study was to develop a method for modeling the transport of EOR chemicals accidentally released to fresh water aquifers. Examples involving hypothetical releases of EOR chemicals at surrogate aquifer sites were used to demonstrate one way in which this method could be applied. The examples were postulated based on typical injection rates and concentrations used at existing EOR projects. Surrogate aquifer sites were used to avoid reference to an actual parcel of land. These sites were, however, based on characteristics and properties of actual aquifers in states where chemical flooding methods are employed.

\subsection{EOR AND GROUND WATER CONTAMINATION}

Chemicals used in EOR may enter aquifers from several routes: corroded casings, improperly completed wells, abandoned wells, subsurface fractures, accidental surface spills, and from surface pits which either seep or are improperly abandoned.

Finding documentation of actual cases of ground water contamination was difficult. Frequently a fresh water aquifer is not being utilized at the time contamination occurs, thus the pollution is discovered after the fact. In such cases there is no record of the source of pollution nor of the quantity which entered the ground. When the contamination occurs over years to decades, such as the leaching of wastes from a storage area or landfill, it is very difficult to determine the initial pollutant concentration and load. Also it is difficult to trace contaminants back to the source and to the date contamination occurred.

Searches to find a documented case of chemical contamination of an aquifer where the initial mass or concentration could be approximated and where the direction and distance of travel was known lead to the conclusion that ground water monitoring in the past has been incomplete. Forty people from five federal offices, eleven states, and a number of universities and private industries were contacted. While several cases of chemical contamination of ground water were found, none was complete in its documentation. A possible case of contamination by a polyacrylamide used in EOR was discovered and monitoring is still being conducted.

Oil and brine contamination often goes undetected due to the isolation of oil fields from populated areas. Officials in several western states declared that while there are no documented cases of ground water contamination from chemical enhanced oil recovery, it was their personal opinion that there are cases which will be discovered when someone needs the water. In the eastern overthrust region of western Pennsylvania, New York, Ohio, and West Virginia where Pennsylvania grade crude oil has been produced for a long time there are frequently residential areas close by. Contamination of drinking water wells by brines and petroleum escaping through improperly abandoned wells is a common occurrence in these areas. 
The presence of EOR chemicals in ground water can be a problem, depending on relative concentration, toxicity, and other related health effects, such as skin irritations or allergic reactions. One particular example is polyacrylamides, which are used as mobility control agents and are essentially non-toxic. The presence, however, of a small quantity of the monomer in solution with hydrolized polyacrylamide would present a health risk because acrylamide monomer is a severe neurotoxin and cumulative poison. Fortunately polyacrylamides are often crosslinked and the chances that monomers will leach out of solution are small; moreover commercial grades of polyacrylamide usually contain only small amounts of acrylamide monomer.

Most of the commonly used chemical cosurfactants are alcohols of the $\mathrm{C}_{5}-\mathrm{C}_{12}$ fatty acids which have low toxicities. Many of the common anionic surfactants are long chain linear alkyl sulfonates, alkyl aryl sulfonates, and petroleum sulfonates which are toxic if ingested, irritating to eyes and skin, and might provide vehicles for the uptake of hazardous chemicals because of their abilities to make those chemicals soluble.

Some of the biocides, bactericides, and oxygen scavengers could present problems if present in solution as ground water contaminants. Some phenolic compounds and their metabolites are toxic, while their co-contaminants, dioxins and furans, have potential long term environmental consequences. Many chemicals used in alkaline flooding or in EOR pre-flushes are caustic or acidic in nature and have substantial health-related effects.

Recently enacted Underground Injection Control regulations require strict procedures for the placement, construction, mechanical integrity, operation, and monitoring of wells. Some hazards posed to field personnel and to populations which use aquifers near or underneath EOR fields as sources of drinking water could thus be reduced substantially. Safe handling and disposal practices and strict adherance to both occupational health and safety and underground injection control regulations would be required.

\subsection{EOR CHEMICALS IN AQUIFERS}

Three EOR methods of concern to this study were micellar-polymer, polymer, and alkaline flooding techniques. These involve an array of chemicals, many of whose behavior in the subsurface (particularly in fresh water aquifers) is not well characterized. As a result more than 40 manufacturers, distributors, and university researchers were contacted to obtain physical and chemical data, including subsurface degradation properties for most commonly used EOR chemicals. Chemical additives such as bactericides and biocides, and alkaline flooding agents were not included in our quantitative analysis because the appearance of these particular contaminants in solution with ground water was not actually the subject of our report. For the same reason, no attempt was made to compile extensive data on the possible combinations of chemicals which might appear as contaminants (e.g., brine containing surfactant, cosurfactant, polymer, and/or scavenger). 
The transport of contaminants in ground water is governed by flow fields and by chemical and biochemical reactions which alter concentrations. Mechanisms include adsorption, desorption, acid-base reactions, solution and precipitation, reduction and oxidation, ion-pairing or formation of complexes, microbial synthesis, and degradation.

Unfortunately, precise data on degradation of EOR solutes are either missing or difficult to obtain. Partially hydrolyzed polyacrylamide solutions change their viscoelastic behavior and degrade mechanically when injection pressures are high. Within the oil reservoir, mechanical degradation affects the mobility of the polymer banks. However, under low pressures at low flow rates like those which might occur in many fresh water aquifers, further degradation of polyacrylamides has not been studied and such degradation might be assumed to be negligible, particularly under aerobic conditions.

Nonionic surfactants like long chain ethoxylated alcohols are used in EOR applications as cosurfactants. The biodegradation of different types of nonionic surfactants has most recently been studied through electrochemical methods based on adsorption phenomena at charged electrodes and based on ${ }^{14} \mathrm{CO}_{2}$ evolution. Studies of the degradability of the anionic surfactants specific to EOR are not available at this time.

There are only a few studies currently investigating bacterial activity in ground water and these have been restricted to shallow recharge aquifers. It is generally presumed, however, that there is considerably less bacterial activity in deep artesian aquifers. A project has recently begun at Brookhaven which will examine biological activity in deep aquifers.

\subsection{GROUND WATER MODELING OF SURROGATE AQUIFER SITES}

Ground water modeling was used to assess the way EOR chemicals would migrate in fresh water aquifers. Such models are very site and application specific. The assumptions used by models accordingly limit their applicability.

The Random-Walk model developed by Prickett et al. was chosen because it can be applied to a wide variety of ground water contamination problems. This model can simulate one- or two-dimensional, steady/non-steady flow and solute transport problems in homogeneous or heterogeneous aquifers under water table and/or confined or semi-confined conditions. In addition, the model can evaluate the impact of time varying pumpage or injection by wells, natural or artificial recharge, water exchange between surface and ground water, the mechanism of flow from springs, and the process of ground water evapotranspiration. The model takes into account advection, dispersion, and chemical reactions.

Surrogate site analysis was used to create a realistic environmental assessment: data were used to deal with site specific impacts without identifying the actual location. Surrogate sites were synthesized from real 
topographic, geologic and hydrologic data combined in such a way as to avoid reference to a specific parcel of land. The use of such sites enables a very realistic assessment of what could happen without identifying anyone involved. The sites for this study were chosen from the collection of states where tertiary oil production methods are used.

Four sites were chosen each representing different geologic ages, rock types, and permeabilities. Analyses were conducted for two separate sets of hypothetical accidents, one involving polyacrylamides and the other petroleum sulfonates. These examples were postulated assuming that the injection well passes through a fresh water formation above the oil reservoir, the well develops a crack, and a small percentage of the injected fluid leaks undetected directly into the aquifer for a short period of time. The wells would be monitored with a certain frequency and once a leak was discovered, injection would be discontinued until the well could be repaired. Each example is treated as a slug release by the model.

The results of these calculations indicate that, after their accidental release to fresh water aquifers during EOR injections, both polymers and petroleum sulfonates may persist for years at very high levels (e.g., hundreds to thousands of $\mathrm{ppm}$ ). The plumes could cover large areas, several hundred feet from their sources, and could be expected to migrate offsite the EOR field depending upon the location of the accident, the initial source strength, and specific aquifer conditions.

\subsection{CONCLUSIONS}

- All methods of enhanced oll recovery involve some risk to ground water. Technologies which involve the injection of chemicals into the reservoir or which fracture formations have a greater chance of an accident occurring. Three general pathways of pollutant discharge into an aquifer are of concern: leaching from the surface, dispersing through imperfect wells, and dispersing through fractures in the formation.

- The risk of contamination is increased when EOR projects take place in old oil fields where unmapped abandoned wells exist. These wells are sometimes poorly, sealed and lead to chemical intrusion, into aquifers. The condition of old wells, which may have cracks in cement or -casing due to age, corrosion, or both, can also pose risks.

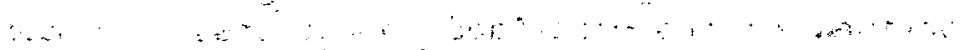

other potential risk sites can occur: where fields are located in areas which have undergone significant subsidence, or which are in seismically active areas. Clearly the risks increase when reservoirs are in close proximity : with aquifers or when the aquifer is near a surface disposal area.

- There is a serious paucity of information concerning the subsurface behavior of EOR chemicals, particularly their behavior in fresh water aquifers. Research is required to determine 
how these chemicals degrade, adsorb, and absorb; and what their daughter products are and how these may pose health risk.

- Models must still be developed to incorporate multiphase and multifluid flow, as well as several mechanisms such as polymer shear degradation and biochemical decay.

- Use of numerical models for available EOR ground water contamination is possible, though each such application is highly site specific. These models usually employ simplifications which may seriously affect their output (e.g., constant head; uniform flow; homogenous, isotropic ground water flow).

- This study provides one method for modeling the migration of contaminants in fresh water aquifers. The examples included in this report illustrate the application of this method and indicate the significant amount of data required to model ground water systems adequately. It is recommended that a user applying this method to a real accident either have field tests performed to characterize the aquifer in question better, or access state files to obtain accurate information enabling calculation of some of the required parameters.

- After their accidental release to fresh water aquifers, both EOR polymers and petroleum sulfonates can be expected to persist for years at levels on the order of hundreds to thousands of ppm. Their contaminated plumes could migrate offsite EOR fields depending upon the location of their source, initial rates of injection and specific aquifer conditions.

- Although the Underground Injection Control (UIC) program requires monitoring of disposal wells, the possiblity of contamination from brine and EOR chemicals in produced waters still exists.

- Safe handling and disposal practices, and strict adherence to both occupational health and safety, and underground injection control regulations could be expected to reduce substantially hazards posed to field personnel and to populations which use aquifers near or underneath EOR operations.

- Documented cases of ground water contaminaton due to EOR are few. Nevertheless several state agencies expect these to increase, particularly with respect to large numbers of poorly abandoned wells whose locations are unknown. 


\section{REFERENCES}

1. T.M. Doscher, "Enhanced Recovery of Crude Oil," American Scientist $\underline{69}(2), 193$ (1982).

2. The Potentials and Economics of Enhanced Oil Recovery, Federal Energy Administration Report, Lewin and Assoc., Inc., B-76/221, Apr. 1976.

3. J. Heinke1, Projections of Enhanced Oil Recovery, 1985-1995, DOE-Energy Information Administration, 011 and Gas Analysis Division, Office of Energy Source Analysis, TR/ES 79-30, Sept. 1979.

4. Enhanced 0i1 Recovery, National Petroleum Council, Dec. 1976.

5. E. Kaplan, M. Garre11, B. Royce, E.F. Riede1, and J. Sathaye, Assessment of Environmenta1 Problems Associated with Increased Enhanced 0il Recovery in the United States, 1980-2000, BNL 51528, Nov. 1981.

6. C. Braxton et al., Potential Environmental Consequences of Tertiary 011 Recovery, Energy Resources Company, Inc., Report to EPA, July 1976. (Ava1lable from NTIS, PB-260-646.)

7. R. Beck, R. Shore, T.A. Scriven, and M. Lindquist, Potential Environmental Problems of Enhanced $0 i 1$ and Gas Recovery Techniques, Energy Resources Company, Inc., Report to EPA, EPA Report IERL-CI-706, Apr. 1980.

8. Environmental Development Plan: Enhanced $0 i 1$ Recovery, DOE/EDP-0048, Nov. 1979.

9. Environmental Readiness Document: Enhanced 0il Recovery, Commercialization Phase III Planning, DOE/ERD-0013, Sept. 1978.

10. Environmental Compliance for Enhanced oil Recovery, Project Planning Document, DOE, Division of Fossil Fuel Extraction, 1979.

11. B. Royce, E. Kaplan, M. Garre11, and T.M. Geffen, Identification of Water Requirements for Selected Enhanced Recovery Methods, BNL 51595, Sept. 1982.

12. A.G. Collins and C.C. Wright, Enhanced 011 Recovery Injection Waters, Bartlesville Energy Technology Center, DOE/BETC/RI-82/5, Apr. 1982.

13. J.S. Fryberger and W.H. Bellis, "Quantifying the Natural Flushout of Aquifers," in Proc. Third National Ground Water Quality Symposium, Las Vegas, Sept. 1977, p. 178-185.

14. K. Young, Pennsylvania Bureau of Water Quality Management, Department of Environmental Resources, private communication, 1983. 
15. T. Prickett, T. Naymik, and C. Lonnquist, A "Random Walk" Solute Transport Model for Selected Groundwater Quality Evaluations, Illinois State Wat er Survey, Champaign, Bu11. 64, 1981.

16. "Gulf Reviews the Problems of Chemical Flooding," Enhanced Recovery Week, p. 4 (May 9, 1983).

17. J.R. Bragg et al., "Loudon Surfactant Flood Pilot Test" (Paper SPE/DOE 10862), in Third Joint SPE/DOE Symp. on Enhanced Oil Recovery, Tulsa, Apr. 1982, p. 933-52.

18. "Exxon Surfactants Get $60 \%$ of Residual 0i1," Enhanced Recovery Week, p. 1 (Apr. 12, 1982).

19. W.B. Gogarty, "Status of Surfactant or Micellar Methods," J. Petroleum Technology 28, 93-102 (Jan. 1976).

20. H.L. Chang, "Polymer Flooding Technology Yesterday, Today, and Tomorrow," J. Petroleum Technology 30,1113-28 (Aug. 1978).

21. E. Silvestro and A. Desmarais, Toxicity of Chemical Compounds Used for Enhanced $0 i 1$ Recovery, Energy Resources Co., Inc., report to Bartlesville Energy Technology Center, DOE/BC/10014-5, 1980.

22. R.A. Freeze and J.A. Cherry, Groundwater, Prentice-Hal1, Inc., Englewood C1iffs, NJ, 1979.

23. Council of Environmental Quality, Contamination of Ground Water by Toxic Organic Chemicals, Jan. 1981 .

24. J. Wilson, Oklahoma State University, private communication, Apr. 25, 1983.

25. J. Meister, H. Pledger Jr., T. Hogen-Esch, and G. Butler, "Retention of Polyacrylamide by Berea Sandstone, Baker Dolomite, and Na Kaolinite During Polymer Flooding" (SPE 8981), in SPE Fifth Int'1. Symp. on Oilfield and Geothermal Chem., Stanford, p. 61, May 1980.

26. S.K. Baijal and N.C. Dey, "Kole of Molecular Parameters During Flow of Polymer Solutions in Unconsolidated Porous Media," J. of Applied Polymer Science 27, 121 (1982).

27. M.P. Anderson, "Using Models to Simulate the Movement of Contaminants through Groundwater Flow Systems," CRC Critical Reviews in Environmental Control 9(2), p.97-156, Nov. 1979 .

28. Dictionary of Scientific and Technical Terms, McGraw-Hill Book Co., 1974.

29. J.T. Wilson and J.F. McNabb, "Biological Transformation of Organic Pollutants in Groundwater," EOS Transactions, American Geophysical Union 64(33), 505 (Aug. 1983). 
30. J.T. Wilson, J.F. McNabb, D.L. Balkwill, and W.G. Ghiorse, "Enumeration and Characterization of Bacteria Indigenous to a Shallow Water-Table Aquifer," Ground Water 21(2), p. 134-142 (Mar. - Apr. 1983).

31. R. Larson and L.M. Games, "Biodegradation of Linear Alcohol Ethoxylates in Natural Waters," Environmental Science and Technology 15(12),1488 (Dec. 1981).

32. R.D. Vashon and B.S. Schwab, "Mineralization of Linear Alcohol Ethoxy1ates and Linear Alcohol Ethoxyl Sulfates at Trace Concentrations in Estuarine Water," Environmental Science and Technology 16(7),433-436 (1982).

33. A.J. Francis, Brookhaven National Laboratory, private communication, May $25,1983$.

34. J. K1ein and A. Westerkamp, "Comparative Adsorption Studies Using Polyacrylamide and a Polysaccharide Type Polymer in Oilfield Oriented Model Systems Simulating Enhanced Oil Recovery Conditions," Die Angewandte Makromolekulare Chemie 92(1413),15 (1980).

35. T. Stutzmann and B. Siffert, "Contribution to the Adsorption Mechanism of Acetamide and Polyacrylamide onto Clays," Clays and Clay Minerals 25 p. 392-406 (1977).

36. J.B. Lawson, "The Adsorption of Non-Ionic and Anionic Surfactants on Sandstone and Carbonate (paper SPE 7052)" in Fifth Symposium on Improved Methods for Oil Recovery, Tulsa, Apr. 1978, p. 159-70.

37. W. Kamirez, F. Friedman, L.C. Denayelle, D.J. Schuler, "Adsorption and Interfacial Tension Dynamics of Surfactants in Porous Media" (paper SPE 9280), in 55th Annual Fall Technical Conference, Society Petroleum Engineers, Dallas, Sept. 1980, P. 1-11.

38. P. Somasundaran and H.S. Hanna, "Adsorption of Sulfonates on Reservoir Rocks" (paper SPE 7059) in Fifth Symposium on Improved Methods in 0i1 Recovery, Tulsa, Apr. 1978, p. 242-52.

39. B.G. Hurd, "Adsorption and Transport of Chemical Species in Laboratory Surfactant Waterflooding Experiments" (paper SPE 5818) in Improved 0il Recovery Symposium, Tulsa, 1976, p. 281-302.

40. J. Novosad, "Surfactant Retention in Berea Sandstone,-- Effects of Phase Behavior and Temperature," Society Petroleum Engineers J. 34(12);962 (Dec. 1982).

41. R.S. Seright, "Effects of Mechanical Degradation and Viscoelastic Behavior on Injectivity of Polyacrylamide Solutions" (paper SPE 9297), in 55th Annual Fall Technical Conference, Society Petroleum Engineers, Dallas, Sept. 1980, p. 1-16. 
42. S.L. Wellington, "Biopolymer Solution Viscosity Stabilization -- Polymer Degradation and Antioxidant Use" (paper SPE 9296), in 55th Annual Fall Technical Conference, Society Petroleum Engineers, Dal 1as, Sept. 1980, p. 1-9.

43. Z. Kozarac, D. Hrsak, and B. Cosovic, "Electroanalytical Determination of the Biodegradation of Nonionic Surfactants," Environmental Science Technology 17,268 (1983).

44. B. Ewen, Wyoming Department of Environmental Quality, private communication, Feb. 16, 1983.

45. W. Gray, Princeton University, private communication, Feb. 10, 1983.

46. C. Kleeman and G. Hoessel, US EPA Region III Pennsylvania, private communication, 1981-1983.

47. P. Lewis and A. McGinley, Texas Water Resources Enforcement and Field Section, private communication, Jan. 25, 1983.

48. 0. Simpson, New Mexico 011 Conservation Division, private communication, Jan. $26,1983$.

49. R. Baker, Long Beach Branch $0 i 1$ and Gas Division of the California State Department of Conservation, private communication, Jan. 25, 1983.

50. J. Sathaye, Lawrence Berkeley Laboratory, private communication, Feb. 9, 1983.

51. J. Carr, USGS Kansas, private communication, Feb. 17, 1983.

52. M. Heidari, Kansas Geological Survey, private communication, Feb. 17, 1983.

53. P. Hynes and R. Lind, US EPA Region I Boston, private communication, Jan. to Mar. 1983.

54. G. Solvas, Division of Mineral Resources New York State Department of Environmental Resources, private communication, Apr. 20, 1983.

55. B. Taylor, New York State Petroleum Council, private communication, Jan. $18,1983$.

56. D. Nielson, National Water Well Association, private communication, Jan. 27 and Feb. 8, 1983.

57. J. Rauder, National Petroleum Council, private communication, Jan. 26, 1983.

58. K. Nash, US EPA Region VI Dallas, private communication, Jan. 19, 1983.

59. D. Smith, Oklahoma Water Resources Board, private communication, Jan. $25,1983$. 
60. R. Beck, B. Aboba, D. Miller and I. Kaklins, Monitoring to Detect Ground Water Problems Resulting from EOR, EPA-600/2-81-241, Oct. 1981 .

61. J.C. Howell and R.E. Porter, Commercial Scale Demonstration EOR by Micellar-Polymer Flood, Annual Report 0ct. 1980-Sept. 1981, DOE/ET/ 13077-63, May 1982.

62. "Mobil Completes Sho-Ve1-Tum Polymer Injection," Enhanced Recovery Week, p. 4, Apr. 11, 1983.

63. "Sho-Vel-Tum Gets Second Polymer Flood," Enhanced Recovery Week, p. 5, Apr. 4, 1983.

64. "Production is Up at Samedann's Polymer Flood," Enhanced Recovery Week, p. 1, Feb. 28, 1983.

65. "Terra Nears Conclusion of Wyo. Polymer Injection," Enhanced Recovery Week, p. 3-4, Apr. 11,1983.

66. "Texaco's Microemulsion Boosts Production at Salem," Enhanced Recovery Week, p. 1, Mar. 7, 1983.

67. "Tenneco Asks TRC to Approve Polymer Flood," Enhanced Recovery Week, p. 1 , Dec. 22, 1980.

68. "Tenneco Unimpressed with Polymers at Panhandle," Enhanced Recovery Week, p. 4, Mar. 28, 1983.

69. "Tex., Wyo., La. Fields get Polymers from Sun," Enhanced Recovery Week, p. 5, Apr. 6, 1981.

70. G.W. Tracy and D.L. Dauben, An Evaluation of the North Burbank Unit Tertiary Recovery Pilot Test, DOE/BC/10033-2, Aug. 1982.

71. L.E. Van Horn, E1 Dorado Micellar Polymer Demonstration Project Sixth Annual Report Sept. 1979 - Aug. 1980, DOE/ET/13070-63, Apr. 1981.

72. J.E. Edwards, Enhanced Oil Recovery by Improved Waterflooding First Annual Report, BETC/2541-12, May 1979 .

73. F.F. Craig III, EOR by Improved Waterflooding Fourth Annual Report Oct. 1980 - Sept. 1981, DOE/ET/12065-52, May 1982 .

74. K.H. Widmyer and R.G. Pindel1, Manvel Enhanced Recovery Pilot Performance Evaluation, SPE/DOE $9793,1981$.

75. OKNL, Environmental Assessment of Gary Operating Co. EOR Project Powder River and Carter Counties, Montana, Dec. 1978.

76. R.F. Kleinschmidt and J.C. Trantham, North Burbank Unit Tertiary Recovery Pilot Test, DOE/ET/13067-60, June 1980 . 
77. A. Goldburg and G.E. Aho, Bell Creek Micellar Polymer Pilot Demonstration Final Report June 1976 - Mar. 1982, DOE/SF/01802-61, Sept. 1982.

78. J.G. Davis, H.H. Ferrell, and W.C. Stewart, Big Muddy Field Low Tension Flood Demonstration Project, Third Annual Report - Apr. 1980 - Mar. 1981, DOE/SF/01424-39, Nov. 1981 .

79. P.S. Ondrusek and W.T. Paynter, Penn Grade Micellar Displacement Project Final Report, DOE/ET/08002-26, Apr. 1982.

80. 40 CFR 146, EPA Criteria and Standards for the Underground Injection Control Program, Apr. 1983.

81. J.W. Mercer and C.R. Faust, Ground-Water Modeling, National Water Well Assoc., 1981.

82. T.A. Prickett, "Ground-Water Computer Models--State of the Art," Ground Water $17(2), 167$ (Mar.-Apr. 1979).

83. J. Bear, Dynamics of Fluids in Porous Media, American Elsevier, New York, 1972 .

84. J.J. Fried, Groundwater Pollution, Elsevier Scientific, Amsterdam, 1975.

85. D.K. Todd, Groundwater Hydrology, 2nd. ed. J. Wiley and Sons, New York, 1980 .

86. C.A. Oster, Review of Ground-Water Flow and Transport Models in the Unsaturated Zone, Pacific Northwest Lab., PNL-4427, prepared for U.S. Nuclear Regulatory Conmission, NUREG/CR-2917, Nov. 1982.

87. J. Wilson and P. Miller, "Two-Dimensional Plume in Uniform Ground Water Flow," ASCE, J. Hydraulics Division 104, HY4, 503-14 (1978).

88. G. Yeh, AT123D: Analytical Transient One-, Two-, and Three-Dimensiona1 Simulation of Waste Transport in the Aquifer System, ORNL-5602, Oak Ridge National Laboratory, Oak Ridge, TN, Mar. 1981.

89. P.C. Trescott, G.F. Pinder, and S.P. Larson, Finite-Difference Model for Aquifer Simulation in Two Dimensions with Results of Numerical Experiments, Book 7, Chapter Cl, US Geological Survey Techniques of Water Resources Investigations, 1976.

90. L.F. Konikow and J.D. Bredehoeft, Computer Model of Two-Dimensional Solute Transport and Dispersion in Ground Water, Book 7, Chapter C2, US Geological Survey Techniques of Water Resources Investigations, 1978.

91. ORNL, Environmental Assessment Cities Services Co. EOR Project Butler County, Kansas, Dec. 1978.

92. ORNL, Environmental Assessment Penn Grade EOR Project McKean County, Pennsylvania, Dec. 1978 . 
93. DOE, Draft Environmental Assessment of DOE/Marathon Commercial Scale Micellar Polymer Flooding EOR Project, Crawford County, Illinois, Dec. 1979.

94. A. Goldburg, H. Price, and T.C. Wesson, Selection of Reservoirs Amenable to Micellar Flooding, $\mathrm{DOE} / \mathrm{BC} / 00048-20, \mathrm{DOE} / \mathrm{BC} / 00051-20$, Dec. 1980.

95. A. Bell and S. Morrison, Analytical Study of the Ogallala Aquifer in Gray County, Texas, Texas Department of Water Resources Report 243, Jan. 1980 .

96. M.L. Maderak, Ground Water Resources of Wheeler and East Gray Counties, Texas, Texas Water Development Board Report 170, May 1973.

97. P.L. Rettman and E.R. Leggat, Ground Water Resources of Gaines County, Texas, Texas Water Development Board Report 15, reprinted Apr. 1982.

98. W.Mi. Sandeen and J.B. Wesselman, Ground Water Resources of Brazoria County, Texas, Texas Water Development Board Report 163, reprinted Dec. 1982 .

99. J.W. Dillard, Availability and Quality of Ground Water in Smith County Texas, Texas Department of Water Resources Bulletin 6302, reprinted July 1982.

100. S. Csallany, Yields of Wells in Pennsylvanian and Mississippian Rocks in Illinios, Illinois State Water Survey Report 55, 1966.

101. J.P. Kempton, W.J. Morse, and A.P. Visocky, Hydrogeologic Evaluation of Sand and Gravel Aquifers for Municipal Ground Water Supplies in EastCentral Illinois, Illinois Department of Energy and Natural Resources Cooperative Ground Water Report 8, June 1982.

102. K. Cartwright, C. S. Hunt, R. D. Brower and W. J. Nelson, "Pore-Water Pressure in the Roof of an Underground Coal Mine in Illinois," Ground Water 21(3), 311-316 (May - June 1983).

103. Illinois State Geological Survey, Map of Illinois, 1967.

104. R. Brower, Illinois Geological Survey, private communication, May 17, 1983.

105. A. Wehrmann, Illinois State Water Survey, private communication, May 19, 1983.

106. M. Lowery, USGS Water Resources Division Wyoming, private communication, May 16, 1983.

107. J. Denne, Kansas Geological Survey Division of Geohydrology, private communication, May 17, 1983. 
108. R.B. Leonard, Chemical Quality of Water in the Walnut River Basin South-Central Kansas, USGS, Water Supply Paper 1982, 1972.

109. J. Ward, A Study of Joint Patterns in Gently Dipping Sedimentary Rocks of South-Central Kansas, State Geological Survey of Kansas Bulletin 191 part 2, 1968.

110. J. Robertson, Chief USGS Hazardous Waste Office, private communication, July $27,1983$.

111. J. Rosenshine, Chief USGS Kansas, private communication, July 28, 1983.

112. T.B. Reed, USGS Kansas, private communication of data from "Compilation and Analysis of Aquifer Performance Tests in Eastern Kansas," USGS Basic Data Series Report (to be published), July 28, 1983.

113. USGS, Map of Kansas, Hydrologic Unit Map 1974, 1976.

114. J.M. Salisbury, G.D. Wickersham, and L.W. Canter, Summary of Major Oklahoma Aquifers, National Center for Ground Water Research, NCGWR 80-37, Nov. 1980 .

115. Oklahoma Geological Survey, Hydrologic Atlas Series Maps HA 1-7, 1969 1977.

116. K. Johnson, Associate Director Oklahoma Geological Survey, private communication, May $17-23,1983$.

117. J.J. D'Lugosz and R.G. McClaflin, Geohydrology of the Vamoosa-Ada Aquifer, East-Central Oklahoma, USGS and Oklahoma Geologica1 Survey Open File Report 81-62, (1981 to be published).

118. D. Isherwood, Geoscience Data Base Handbook for Modeling a Nuclear Waste Repository, Vol. 1, Lawrence Livermore Lab., UCRL-52719, 1981.

119. J. Keely, Robert S. Kerr Research Lab., Ada, Oklahoma, private communication, Jan. 27 and Feb. 11, 1983. 